\title{
STUDIES OF SOLAR FLARES USING OPTICAL, X-RAY AND RADIO DATA
}

\author{
H. ZIRIN* \\ Big Bear Solar Observatory, Hale Observatories, Carnegie Institution of Washington, California Institute \\ of Technology, Pasadena, Calif. 91101, U.S.A.
}

(Received 9 May, 1977; in final form 20 March, 1978)

\begin{abstract}
I have studied a number of flares for which good X-ray and optical data were available. An average lag of $5.5 \mathrm{~s}$ between hard X-ray (HXR) start and $\mathrm{H} \alpha$ start, and HXR peak and $\mathrm{H} \alpha$ peak was found for 41 flares for which determination was possible. Allowing for time constants the time lag is zero. The peak $\mathrm{H} \alpha$ lasts until 5-6 keV soft X-ray (SXR) peak. The level of $\mathrm{H} \alpha$ intensity is determined by the SXR flux.

Multiple spikes in HXR appear to correspond to different occurrences in the flare development. Flares with HXR always have a fast $\mathrm{H} \alpha$ rise. Several flares were observed in the $\lambda 3835$ band; such emission appears when the 5.1-6.6 keV flux exceeds $5 \times 10^{4} \mathrm{ph} \mathrm{cm}^{-2} \mathrm{~s}^{-1}$ at the Earth. Smaller flares produce no $\lambda 3835$ emission; we conclude that coronal back conduction cannot produce the bright chromospheric network of that wavelength.

The nearly simultaneous growth of $\mathrm{H} \alpha$ emission at distant points means an agent travelling faster than $5 \times 10^{3} \mathrm{~km} \mathrm{~s}^{-1}$ is responsible, presumably electrons.

In all cases near the limb an elevated $\mathrm{H} \alpha$ source is seen with the same time duration as HXR flux; it is concluded that this $\mathrm{H} \alpha$ source is almost always an elevated cloud which is excited by the fast electrons. A rough calculation is given. Another calculation of $\mathrm{H} \alpha$ emission from compressed coronal material shows it to be inadequate.

In several cases homologous flares occur within hours with the same X-ray properties.

Radio models fit, more or less, with field strengths on the order of $100 \mathrm{G}$. A number of flares are discussed in detail.
\end{abstract}

\section{Introduction}

Hard X-ray and radio data provide important information on the magnetic components of solar flares, but at present no spatial information is available. Optical observations, on the other hand, give us high spatial resolution on radiations which may also be excited by the flare electrons. The subject of this paper is to see what can be extracted about the flare from the combination of these data using better and more extensive recent data.

The material used here draws upon optical data in $\mathrm{H} \alpha$ and at $\lambda 3835 \AA$ obtained at the Big Bear Solar Observatory, and X-ray data provided by K. Frost (OSO-5), L. Peterson (OSO-7), S. Kane (OGO-5), and P. Hoyng (ESRO TD-1A). The flares identified as the sources of $\mathrm{X}$-ray bursts are chosen purely by time coincidence; we have only studied events where there was no ambiguity.

The relation between optical, X-ray and microwave data has been studied by many authors, inter alia Zirin et al. (1971) and Vorpahl (1972). Although correlation has always been found, there have been discrepancies. The more recent

* Author's address: Solar Astronomy 264-33, California Institute of Technology, Pasadena, Calif. 91125, U.S.A. 
optical and X-ray data studied here permit much more accurate determination of time delays, intensities, and flare morphology.

Examination of the optical appearances of X-ray flares is an excellent opportunity for an unbiased study of flare structure, without regard for 'favorite' flares. In fact, flares of the most varied appearance are seen. Many, indeed most, of the flares occurred near some field anomaly, but some, like the 16 December, 1972 (Section $4 \mathrm{e}$ ) flare, just squirt out of sunspots. In the flares above the limb, or just inside the limb, vertical extension or structure is seen in every case. In some of these, a double (2 strand) structure, unconnected by $\mathrm{H} \alpha$ emission, is occasionally observed (10 February, 1972). But the vertical structure is rarely apparent in flares on the disk; usually radiation is only seen from 2 or more apparently flat regions at the ends of force lines. About 70 flares were studied, of which 41 had good data. Some are described below in detail.

The principal conclusions (some of which have already been pointed out by others) are:

(i) There is a good correspondence between the rise and peak of the $\mathrm{H} \alpha$ emission and the hard X-ray flux (HXR defined as above $20 \mathrm{keV}$ ), within a few seconds. In a few cases the $\mathrm{H} \alpha$ flux peaks at the end of the HXR burst, but in $95 \%$ the two march together. If there is a lag between the hard X-ray burst and the soft $X$-ray (SXR about $5 \mathrm{keV}$ ) burst, the $\mathrm{H} \alpha$ remains at peak until after the SXR peak. We do not see the $20 \mathrm{~s}$ lag found by Vorpahl (1972).

(ii) The $\mathrm{H} \alpha$ surface brightness of HXR and SXR bursts was measured and found to be the same for bursts of the same SXR flux.

(iii) All multiple spikes studied corresponded to different steps in the development of the optical flare.

(iv) Flares with HXR are characterized by a rapid rise to maximum of $\mathrm{H} \alpha$ or HXR, usually less than $10 \mathrm{~s}$.

(v) Flares are observed in $\lambda 3835$ if the OSO-7 flux is greater than $5 \times 10^{4} \mathrm{ph}$ $\left(\mathrm{cm}^{2} \mathrm{~s} \mathrm{keV}\right)^{-1}$ in the $5.1-6.6 \mathrm{keV}$ channel.

Smaller flares produce no observed brightening. This is strong evidence that the low chromospheric network is not heated by conduction from above.

(vi) I find that the flare $\mathrm{H} \alpha$ emission can be explained by direct excitation of a preflare cloud or prominence by the flare electrons and their secondaries. In all cases in which flares were observed near the limb the $\mathrm{H} \alpha$ emission came from an elevated source and the interaction of the electrons with that cloud appears to excite $\mathrm{H} \alpha$ directly.

(vii) The impulsive growth of $\mathrm{H} \alpha$ emission in various distant sections of the flares studied occurs within seconds, proving that it must be produced by something moving at least $5000 \mathrm{~km} \mathrm{~s}^{-1}$; this strongly supports the Lin-Hudson (1976) model of the electrons as the primary energy bearers.

(viii) In numerous cases nearly identical flares occur within hours. The general magnetic features are therefore not destroyed. 
In the next section I describe the data and measurement results; in the third, I discuss observations in $\lambda 3835$; in the fourth, specific flares are described. In Section 5 I discuss the photometric measurements, and in Section 6 the mechanisms for $\mathrm{H} \alpha$ excitation.

\section{Data and Comparison}

X-ray data are now available from a number of spacecraft, dating back to 1968; the various investigators have been most kind in furnishing copies of their data. The OGO-5 data (Kane and Anderson, 1970) has $3.2 \mathrm{~s}$ time resolution and good time coverage, but suffered from pileup and did not operate for long after Big Bear high resolution observations began. The OSO-5 data (Frost et al., 1971) have high time resolution (1.2 s) and no pileup, but are relatively insensitive, so there are not many events we could use. The OSO-7 data have only $10 \mathrm{~s}$ time resolution but many energy channels, both soft and hard, and good sensitivity. The TD-1A data (Hoyng, 1975) are similar to the OSO-5 data. The OSO-5 and TD-1A experiments give no information on SXR; OGO-5 gives uncalibrated SXR data through pileup; OSO-7 gives unambiguous data on all channels, but only for small flares [5.1-6.6 keV flux $\left.\leqslant 10^{4}\left(\mathrm{~cm}^{2} \mathrm{~s} \mathrm{keV}\right)^{-1}\right]$. The OSO-7 data have been completely reduced and are in readily accessible form for comparison with observation. Hence most comparisons are made with them. All hard X-ray data ceased in the middle of 1973.

The Big Bear optical data began in October 1969, with one wavelength. A second simultaneous wavelength (usually the wing of $\mathrm{H} \alpha$, referred to as 'off band', but sometimes K-line or a broad band filter at $\lambda 3835 \AA$ ) was added in 1971 , and a third, at the beginning of 1973. In addition a full disk telescope was used from 1971 on in $\mathrm{H} \alpha$, as well as small patrol instruments covering about $\frac{1}{4}$ of the disk at Caltech and Tel Aviv. Although these instruments show many more flares, the spatial resolution is lower and they have not been used here. These data are available to those interested.

The time measurements for 41 flares are presented in Table I. For each case, $\mathrm{H} \alpha$ data are given in the first row, $\mathrm{X}$-ray in the second. In a few cases $\lambda 3835$ data are given also. The model flare shows a precursor, marked by a gradual increase in $\mathrm{H} \alpha$ and SXR; an impulsive phase which we define as the time of most rapid increase in $\mathrm{H} \alpha$ and HXR intensity; a maximum, which is usually a plateau reached at the impulsive phase; and a decline, with HXR dropping rapidly but SXR and $\mathrm{H} \alpha$ remaining high. We have paired the corresponding $\mathrm{H} \alpha$ and $\mathrm{HXR}$ measurements in the table accordingly. In all the flares (except a few gradual ones) the impulsive times were measured; in some there was no precursor, and in some the end was indeterminate or cut off by clouds, in which case no data are given.

In every case times were measured by viewing $\mathrm{H} \alpha$ films and making two consecutive determinations. Then times were scaled from X-ray plots. Although gradual effects, such as precursors and ends of flares cannot be accurately timed, the timing 


\section{TABLE I}

Comparison of $\mathrm{H} \alpha$ and $\mathrm{X}$-ray time determination (for each flare, $\mathrm{H} \alpha$ is the top row)

\begin{tabular}{|c|c|c|c|c|c|c|}
\hline Date & Precursor & Impulsive & Max. & $\frac{\text { End max. }}{\text { End } H X R}$ & $\begin{array}{c}\begin{array}{c}\text { End } \\
\text { gradual }\end{array} \\
\text { End SXR }\end{array}$ & Remarks \\
\hline May 22,1970 & $\begin{array}{l}\mathrm{H} \alpha \\
\mathrm{X} \text {-ray }\end{array}$ & $\begin{array}{l}18: 58: 00 \\
18: 58: 20\end{array}$ & $\begin{array}{l}19: 00 \\
19: 00\end{array}$ & $\begin{array}{l}19: 01 \\
19: 01\end{array}$ & $\begin{array}{l}19: 04 \\
19: 04\end{array}$ & $\begin{array}{l}2 \mathrm{~d} \text { event } \\
\text { 19:04, surge }\end{array}$ \\
\hline May 22, 1970 & & $\begin{array}{l}20: 33 \\
20: 33\end{array}$ & $\begin{array}{l}20: 36 \\
20: 33\end{array}$ & & & \\
\hline May 26,1970 & $\begin{array}{l}17: 35 \\
17: 35\end{array}$ & $\begin{array}{l}17: 40: 25 \\
17: 41: 00\end{array}$ & $\begin{array}{l}17: 41: 40 \\
17: 41: 20\end{array}$ & $\begin{array}{l}17: 43 \\
17: 41: 20\end{array}$ & $\begin{array}{l}17: 45 \\
17: 48\end{array}$ & \\
\hline May 28,1970 & $01: 21: 22$ & $\begin{array}{l}01: 21: 21 \\
01: 21: 20\end{array}$ & $\begin{array}{l}01: 21: 55 \\
10: 21: 30\end{array}$ & & & $\begin{array}{l}\text { soft burst } 01: 23 \\
\text { with surge }\end{array}$ \\
\hline June 15,1970 & & $\begin{array}{l}18: 37: 36 \\
18: 37: 50\end{array}$ & $\begin{array}{l}18: 38: 19 \\
18: 38: 22\end{array}$ & $\begin{array}{l}18: 40 \\
18: 38: 37\end{array}$ & & \\
\hline June 28,1970 & $\begin{array}{l}19: 40 \\
19: 40\end{array}$ & $\begin{array}{l}20: 00: 55 \\
20: 00: 46\end{array}$ & $\left.\begin{array}{l}20: 01: 20 \\
20: 01: 20\end{array}\right\}$ & $2 \mathrm{dpk}$ & & $\begin{array}{l}\text { 20:03 Moreton } \\
\text { Wave }\end{array}$ \\
\hline July 22,1970 & $\begin{array}{l}19: 39: 40 \\
19: 39: 45\end{array}$ & $\begin{array}{l}19: 40: 15 \\
19: 40: 13\end{array}$ & & & & \\
\hline Sept. 11,1970 & & $\begin{array}{l}23: 07: 21 \\
23: 07: 30\end{array}$ & $\begin{array}{l}23: 07: 52 \\
23: 07: 55\end{array}$ & $\begin{array}{l}23: 08: 30 \\
23: 08: 05\end{array}$ & & $\begin{array}{l}\text { sequence of flares; } \\
\text { see Section } 4 a\end{array}$ \\
\hline Sept. 11,1970 & & $\begin{array}{l}23: 09: 46 \\
23: 09: 48\end{array}$ & $\begin{array}{l}23: 10: 33 \\
23: 10: 12\end{array}$ & $\begin{array}{l}23: 13 \\
23: 10: 20\end{array}$ & & \\
\hline Sept. 11,1970 & & $\begin{array}{l}23: 15: 33 \\
23: 15: 36\end{array}$ & $\begin{array}{l}23: 15: 55 \\
23: 15: 50\end{array}$ & $\begin{array}{l}23: 16: 05 \\
23: 16: 05\end{array}$ & & \\
\hline Nov. 24,1971 & $\begin{array}{l}18: 53: 45 \\
18: 53: 45\end{array}$ & $\begin{array}{l}18: 57: 10 \\
18: 56: 30\end{array}$ & $\begin{array}{l}18: 58: 10 \\
18: 57-8\end{array}$ & $\begin{array}{l}19: 02 \\
18: 59\end{array}$ & $19: 10$ & \\
\hline Jan. 18, 1972 & $\begin{array}{l}20: 02: 53 \\
20: 03: 00\end{array}$ & $\begin{array}{l}\text { in } \lambda \text { scan } \\
20: 04\end{array}$ & $\begin{array}{l}20: 05 \\
20: 04\end{array}$ & $\begin{array}{l}20: 10 \\
20: 05\end{array}$ & $\begin{array}{l}20: 25 \\
20: 20\end{array}$ & \\
\hline Jan. 19, 1972 & $\begin{array}{l}16: 29 \\
16: 32: 30\end{array}$ & $\begin{array}{l}16: 38 \\
16: 36.5\end{array}$ & $\begin{array}{l}16: 42 \\
16: 42\end{array}$ & & & \\
\hline Feb. 10, 1972 & $\begin{array}{l}23: 15 \\
23: 06\end{array}$ & $\begin{array}{l}23: 29 \\
23: 26.4\end{array}$ & $\begin{array}{l}23: 42 \\
23: 30\end{array}$ & & & $\begin{array}{l}\text { only low time } \\
\text { res. X-ray } \\
\text { available }\end{array}$ \\
\hline Feb. 22, 1972 & & $\begin{array}{l}18: 29: 55 \\
18: 31\end{array}$ & $\begin{array}{l}18: 31 \\
18: 37\end{array}$ & & & \\
\hline May 18,1972 & $14: 04: 45$ & $14: 06: 03$ & $\begin{array}{l}14: 06: 30 \\
14: 06: 20\end{array}$ & & & $\begin{array}{l}\text { two homologous } \\
\text { flares }\end{array}$ \\
\hline May 18,1972 & $16: 16: 58$ & $\begin{array}{l}10: 17: 15 \\
16: 17: 05\end{array}$ & $\begin{array}{l}16: 17: 45 \\
16: 17: 45\end{array}$ & & & Figure 10 \\
\hline June 17,1972 & $\begin{array}{l}00: 00: 00 \\
00: 00: 00\end{array}$ & $\begin{array}{l}00: 02: 00 \\
00: 01: 30\end{array}$ & $\begin{array}{l}00: 03: 00 \\
00: 02: 40\end{array}$ & $\begin{array}{l}\text { end } \max \\
00: 03: 30 \\
00: 02: 50\end{array}$ & & ends in surge \\
\hline
\end{tabular}


Table I (continued)

\begin{tabular}{|c|c|c|c|c|c|c|}
\hline Date & Precursor & Impulsive & Max. & $\frac{\text { End max. }}{\text { End HXR }}$ & $\begin{array}{c}\begin{array}{c}\text { End } \\
\text { gradual }\end{array} \\
\text { End SXR }\end{array}$ & Remarks \\
\hline Aug. 1, 1972 & & $\begin{array}{l}16: 28: 04 \\
16: 28: 04\end{array}$ & $\begin{array}{l}16: 28: 14 \\
16: 28: 14\end{array}$ & $\begin{array}{l}16: 28: 24 \\
16: 28: 24\end{array}$ & & \\
\hline $\begin{array}{l}\text { Aug. 2, } 1972 \\
\qquad(\mathrm{H} \alpha\end{array}$ & $\begin{array}{l}(3835) \\
18: 38: 00 \\
(\text { HXR })\end{array}$ & $\begin{array}{l}18: 39: 04 \\
18: 38: 50 \\
18: 39: 02\end{array}$ & $\begin{array}{l}18: 39: 44 \\
18: 39: 22 \\
18: 39: 40\end{array}$ & & & \\
\hline Aug. 19, 1972 & $\begin{array}{l}(3835) \\
\mathrm{H} \alpha \\
\mathrm{HXR}\end{array}$ & $\begin{array}{l}14: 33: 30 \\
14: 32: 51 \\
14: 32: 57\end{array}$ & $\begin{array}{l}14: 34: 09 \\
14: 34: 04 \\
14: 34: 00\end{array}$ & $\begin{array}{l}14: 34: 30 \\
14: 39 \\
14: 37\end{array}$ & & \\
\hline Sept. 21,1972 & $\begin{array}{l}16: 42 \\
16: 41: 36\end{array}$ & $\begin{array}{l}16: 44: 40 \\
16: 45: 24\end{array}$ & $\begin{array}{l}16: 45: 40 \\
16: 45: 40\end{array}$ & $\begin{array}{l}16: 47 \\
16: 48\end{array}$ & $\begin{array}{r}17: 05 \\
>17: 10\end{array}$ & \\
\hline Oct. 23,1972 & $19: 26: 20$ & $\begin{array}{l}19: 28: 48 \\
19: 28: 04\end{array}$ & $\begin{array}{l}19: 28: 48 \\
19: 28: 59\end{array}$ & $\begin{array}{l}19: 29: 15 \\
19: 29: 20\end{array}$ & $\begin{array}{l}19: 29: 30 \\
19: 31\end{array}$ & \\
\hline Oct. 24,1972 & $15: 22$ & $\begin{array}{l}15: 24: 55 \\
15: 25: 58\end{array}$ & $\begin{array}{l}15: 26: 30 \\
15: 26: 08\end{array}$ & $\begin{array}{l}15: 27: 15 \\
15: 26: 39\end{array}$ & & SXR max same \\
\hline Oct. 24,1972 & & $\begin{array}{l}15: 40: 42 \\
15: 40: 40\end{array}$ & $\begin{array}{l}15: 42: 20 \\
15: 41: 00\end{array}$ & $\begin{array}{l}15: 42: 20 \\
15: 41: 30\end{array}$ & & \\
\hline Oct. 24,1972 & $18: 00: 22$ & $\begin{array}{l}18: 01: 01 \\
18: 00: 08\end{array}$ & $\begin{array}{l}18: 01: 40 \\
18: 00: 34\end{array}$ & $\begin{array}{l}18: 01: 40 \\
18: 01: 50\end{array}$ & & \\
\hline Oct. 25,1972 & $20: 56$ & $\begin{array}{l}20: 57: 52 \\
20: 57: 48\end{array}$ & $\begin{array}{l}20: 59: 45 \\
>20: 58: 40\end{array}$ & & & \\
\hline Oct. 25,1972 & $\begin{array}{l}21: 52 \\
21: 56\end{array}$ & $\begin{array}{l}21: 57: 26 \\
21: 57: 25\end{array}$ & $\begin{array}{l}21: 57: 56 \\
21: 57: 35\end{array}$ & $\begin{array}{l}22: 03 \\
21: 57: 46\end{array}$ & $22: 07$ & $\mathrm{H} \alpha=4.8$ \\
\hline Oct. 25,1972 & $23: 26: 13$ & $\begin{array}{l}23: 27: 20 \\
23: 27: 22\end{array}$ & $\begin{array}{l}23: 28: 12 \\
23: 28: 03\end{array}$ & $\begin{array}{l}23: 28: 15 \\
23: 28: 13\end{array}$ & $23: 31$ & $\mathrm{H} \alpha=5.6$ \\
\hline Oct. 25,1972 & $23: 42: 15$ & $\begin{array}{l}\text { steady rise } \\
23: 42: 23\end{array}$ & $\begin{array}{l}23: 44: 42 \\
\text { const. to } \\
23: 43: 55\end{array}$ & $23: 44: 56$ & $23: 49$ & \\
\hline Nov. 2, 1972 & & $\begin{array}{l}16: 37: 04 \\
16: 36: 54\end{array}$ & $\begin{array}{l}16: 37: 20 \\
16: 37: 04\end{array}$ & $\begin{array}{l}16: 39 \\
16: 37: 35\end{array}$ & & $\mathrm{H} \alpha=5.6$ \\
\hline Dec. 16,1972 & $\begin{array}{l}20: 54: 55 \\
20: 54: 50\end{array}$ & $\begin{array}{l}\text { steady rise to } \\
\text { steady rise to }\end{array}$ & $\begin{array}{l}20: 58 \\
20: 58\end{array}$ & $\begin{array}{l}21: 02 \\
21: 02\end{array}$ & & Fig. 7 \\
\hline Jan. 7, 1973 & $22: 30: 25$ & $\begin{array}{l}22: 32: 04 \\
22: 32: 00\end{array}$ & $\begin{array}{l}22: 33: 24 \\
22: 32: 40\end{array}$ & $\begin{array}{l}22: 34: 03 \\
22: 34: 20\end{array}$ & & \\
\hline Jan. 13, 1973 & & $\begin{array}{l}23: 35: 19 \\
23: 35: 20\end{array}$ & $\begin{array}{l}23: 35: 54 \\
23: 35: 40\end{array}$ & $\begin{array}{l}22: 41 \\
22: 36: 20\end{array}$ & & \\
\hline Mar. 16, 1973 & & $\begin{array}{l}20: 26: 55 \\
20: 26: 30\end{array}$ & $\begin{array}{l}20: 27: 25 \\
20: 27: 10\end{array}$ & $\begin{array}{l}20: 32 \\
20: 27: 50\end{array}$ & & \\
\hline Apr. 8, 1973 & $22: 41: 17$ & $\begin{array}{l}22: 42: 00 \\
22: 42: 00\end{array}$ & $\begin{array}{l}22: 42: 30 \\
\text { const. to }\end{array}$ & $\begin{array}{l}22: 43: 30 \\
22: 43: 30\end{array}$ & $\begin{array}{l}22: 44: 45 \\
22: 50\end{array}$ & $\mathrm{H} \alpha=4$ \\
\hline
\end{tabular}


Table I (continued)

\begin{tabular}{|c|c|c|c|c|c|c|}
\hline Date & Precursor & Impulsive & Max. & $\frac{\text { End max. }}{\text { End HXR }}$ & $\frac{\text { End } H \alpha}{\text { End } S X R}$ & Remarks \\
\hline Apr. 12, 1973 & $\begin{array}{l}22: 09 \\
22: 10: 30\end{array}$ & $\begin{array}{l}22: 12 \\
22: 12\end{array}$ & $\begin{array}{l}22: 13: 06 \\
22: 13: 50\end{array}$ & $\begin{array}{l}22: 17 \\
72: 23: 0\end{array}$ & & \\
\hline Apr. 16, 1973 & $19: 37$ & $\begin{array}{l}19: 41: 30 \\
19: 41: 40\end{array}$ & $\begin{array}{l}19: 41: 55 \\
19: 42: 00\end{array}$ & $\begin{array}{l}\text { NM } \\
19: 43: 20\end{array}$ & & \\
\hline Apr. 16, 1973 & & $\begin{array}{l}21: 31: 57 \\
21: 31: 45\end{array}$ & $\begin{array}{l}\text { same } \\
21: 32: 10\end{array}$ & $\begin{array}{l}21: 32: 22 \\
21: 32: 10\end{array}$ & & \\
\hline Apr. 22, 1973 & $\begin{array}{l}21: 45 \\
21: 46\end{array}$ & $\begin{array}{l}21: 48: 20 \\
21: 48\end{array}$ & $\begin{array}{l}21: 52 \\
21: 50\end{array}$ & & & \\
\hline Apr. 24, 1973 & $\begin{array}{l}19: 22 \\
19: 22\end{array}$ & $\begin{array}{l}19: 27 \\
19: 27\end{array}$ & $\begin{array}{l}\text { 19:28:30 } \\
\text { 19:29 (pileup }\end{array}$ & & $\begin{array}{l}19: 31 \\
19: 40\end{array}$ & $\begin{array}{l}\text { pulses of } H \alpha @ \\
19: 27: 15,27: 45, \\
28: 30\end{array}$ \\
\hline May 6, 1973 & & $\begin{array}{l}14: 57: 08 \\
14: 57: 00\end{array}$ & $\begin{array}{l}14: 57: 37 \\
14: 57: 40\end{array}$ & $\begin{array}{l}14: 58: 30 \\
14: 58\end{array}$ & & \\
\hline
\end{tabular}

of impulsive steps was easy; the rise to maximum usually occurs in one or two $\mathrm{H} \alpha$ frames. This can be seen from the examples in Section 4.

The HXR onset and impulsive $\mathrm{H} \alpha$ brightening times agreed closely. The average for all flares measured was $4.75 \mathrm{~s} \mathrm{H} \alpha$ lag with a standard deviation of $36 \mathrm{~s}$; the standard deviation of the mean is $5.8 \mathrm{~s}$. If we recall that $\mathrm{H} \alpha$ frames were made every 10 or $15 \mathrm{~s}$, and an event not recorded till it is seen on the film, whereas the $\mathrm{X}$-ray data not only has shorter time constants (except for OSO-7 which has $10 \mathrm{~s}$ ), but integrates what has happened in that time constant, we see that an observational $5 \mathrm{~s}$ lag was to be expected, and we may conclude there is zero lag, either for onset or peak. I believe there is no significance to the few cases with more than $60 \mathrm{~s}$ time difference; in these cases either seeing was not good, or there was some question of the exact start. In all cases with good data, the difference was only a few seconds. This can be judged from the illustrations.

In most flares the peak brightness in $\mathrm{H} \alpha$ is reached at the maximum of the hard $\mathrm{X}$-ray burst. In a few flares, the peak $\mathrm{H} \alpha$ intensity occurs at the end of the HXR burst, as though we see the integral of the flux. In flares for which the SXR peak lags the HXR peak, the $\mathrm{H} \alpha$ remains at peak intensity until the SXR peak. The $\mathrm{H} \alpha$ intensity in disk flares rises with the HXR flux and falls with the SXR flux.

In some impulsive flares the $\mathrm{H} \alpha$ goes up and down with the hard X-rays, sometimes with less than $30 \mathrm{~s}$ total duration. Except that all the limb flares show this, I could not detect any special characteristics for flares with this fast optical decay; it appears that the $\mathrm{H} \alpha$ emission we see after the HXR burst ends is due to chromospheric heating by the thermal electrons. Only the flash phase is visible at the limb, produced by excitation of elevated structures. In spectra, the flash phase is recognized by very broad $\mathrm{H} \alpha$ emission, the thermal phase by narrow emission. 
Flares with filament eruptions have long decays, presumably because material goes high, where density is low and lifetime long. Almost all HXR flares show a fast rise $(<30 \mathrm{~s})$ and SXR flares, a slow rise.

In about 10 flares the $\mathrm{H} \alpha$ intensity was measured photometrically relative to a calibrated step wedge developed with the original film. The variation of $\mathrm{H} \alpha$ intensity with time agreed with visual estimates, but I believe the latter more reliable. The $\mathrm{H} \alpha$ intensity relative to line center is given in the Remarks column where measured.

In many flares with 2 strands there is an impulsive brightness increase, simultaneous in fairly distant points (see description of the 18 May, 1972 flare, Section 4). This can only be explained if the energy is carried by fast-moving particles, which must be electrons. On the other hand, in some large flares (28 June, 1970, below; 7 August, 1972, Zirin and Tanaka, 1973) there is a definite evolution of the flare, with a primary energy release and new explosions in different places, leading to the growth of a large flare. In that case a multiple X-ray burst is observed. The agent which triggers the release moves about $500 \mathrm{~km} \mathrm{~s}^{-1}$ and may be an MHD wave or a blast wave.

Comparison with radio data for a number of events showed general agreement in time and intensity of X-ray and radio bursts with the exception of the 11 September, 1970 burst described in Section 4. Impulsive bursts (IXB's in Hoyng) show much higher fluxes and peak frequencies than slow bursts. In complex bursts, such as 28 June, 1970 the $\mathrm{cm}$-wave time profile tracks the HXR time profile perfectly. Low-lying bursts often showed a low frequency cutoff in accordance with the results of Zirin et al. (1971).

I fitted some observed radio spectra and optical areas to the Ramaty-Petrosian (1972) curves, assuming the $\mathrm{H} \alpha$ and radio emitting areas were the same. The fits are good for fields around $100 \mathrm{G}$, although there is, to be sure, much flexibility. For example, the parameters derived from the 5 May, 1972 flare were $A \sim 3 \times 10^{18} \mathrm{~cm}^{2}$, $B \sim 50 \mathrm{G}, S \sim 200 \mathrm{sfu}, \nu_{\max }=5 \times 10^{9} \mathrm{~s}^{-1}$. In this case free-free absorption dominates Razin effect and self-absorption for $T<10^{6}$.

\section{Measurements at $\lambda \mathbf{3 8 3 5}$}

Chapman (1970) introduced the use of a broad filter, about $15 \AA$ wide, centered at $\lambda 3835$, where a series of strong absorption lines makes the low chromosphere somewhat opaque. Chapman, Fisher and Pope (private communication) observed brightening at this wavelength in a class 2 flare, and none in another. However they had a small image and could have missed small brightenings. Zirin (1972) observed some class 1 flares with no brightening in $\lambda 3835$, concluding from this that if even the heating of a solar flare could not produce chromospheric brightening it was unlikely that downward conduction from the ordinary corona could produce the quiet Sun network observed in $\lambda 3835$. Further observations have confirmed Chapman's conclusion that brightening could be observed only in more intense 
flares: we now have 4 cases of brightening observed at Big Bear, all in very intense flares. In one case we have fast flashes corresponding to an impulsive event, while in the other three, the emission is diffuse, long-lived and connected in time with soft $\mathrm{X}$-rays. In each case emission is only observed in the most intense part of the flare. A number of smaller flares produced no $\lambda 3835$ emission.

Observations of fast flashes at $\lambda 3835 \AA$ in the 2 August, 1972 flare were reported by Zirin and Tanaka (1973). We can reexamine these and other observations at the same wavelength. The 2 August, 1972 flare, in which the fast flashes were observed was observed in hard X-rays by TD-1A (Hoyng, 1975). The $\lambda 3835$ and hard X-ray data are shown in Figure 1. The times of the prints are indicated by arrows at the bottom of the X-ray plot. There is a fairly good correlation, if one considers that the $X$-ray detector gives the sum of $X$-rays at all points at any time. Roy (1976) has argued against the simultaneity of the HXR and $\lambda 3835$ flashes; but his arguments are based on a figure (his Figure 4) which uses data obtained by Zirin and Tanaka for the late flashes only. Flashes are clearly seen in Figure 1 at 18:39:04 and the peak X-ray spikes coincide with the development of a whole series of flashes starting 18:39:24. Even the optical flash at 18:39:24 can be matched with a spike in the $29-41 \mathrm{keV}$ channel. There is also a long-lived bright point at the bottom of the spot, which is lost in reproduction, lasting from 18:39:25 to $18: 40: 20$, and which appears unrelated to the HXR.

This flare was a highly unusual event, extremely impulsive. Correspondingly the HXR was unusually spiky. The lieftime of the flashes was only 5 or $10 \mathrm{~s}$, although those seen against the photosphere lasted about a minute. There appears no way to understand this phenomenon other than beamed particles; the simultaneity of onset at several points requires a high velocity, more than $10000 \mathrm{~km} \mathrm{~s}^{-1}$, and the simultaneity with HXR suggests the hard electrons.

In addition to the 2 August flare, we have observations of several other flares in $\lambda$ 3835. These appear quite different; in each case the emission is diffuse, longer lived and correlatee in time with the SXR emission. The most remarkable property of the Chapman filter is its ability to induce flares in the Sun; 2 August was the only day it was operated between 1 January and 15 August. In each case that a flare was observed in $\lambda 3835$ the threshold was $\geq 5 \times 10^{4} \mathrm{ph}\left(\mathrm{cm}^{2} \mathrm{~s} \mathrm{keV}\right)^{-1}$ in the $5.1-6.6 \mathrm{keV}$ channel. The observations in the third flare of 2 August have already been published by Zirin and Tanaka (1973). A slowly moving wave, lasting from 20:37 to 21:00, was associated with the front of spreading $\mathrm{H} \alpha$. The lifetime of the $\lambda 3835$ excitation at each point in this wave was about 90 s. Later in August 1972 the filter was used again for a few days, and one event (Figure 2) was seen on 19 August. Although the HXR falls rapidly after max, the $\lambda 3835$ enhancement lasts more than $6 \mathrm{~min}$, essentially as long as the SXR event (because of saturation the time profile of the SXR is not well known, but we know it was above $10^{4}$ counts). A similar effect was found in a large flare on 26 April, 1973; in that case we do not have complete $\mathrm{X}$-ray data, but the $\lambda 3835$ emission began just as the microwave burst rose to peak. I measured photometrically the peak $\mathrm{H} \alpha$ intensity through the flare, and found that 


\section{AUG.2, 72}

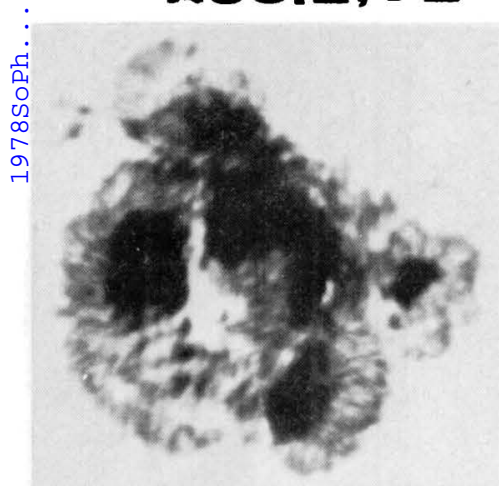

$18: 39: 04$

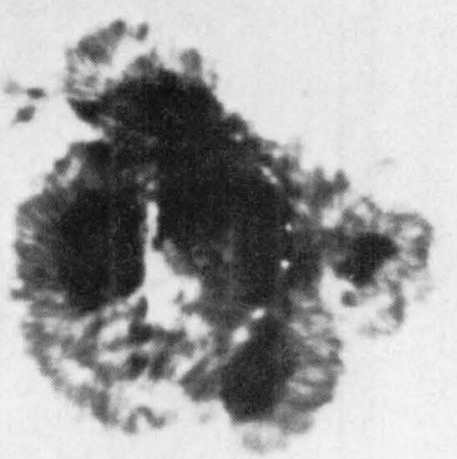

$18: 39: 14$

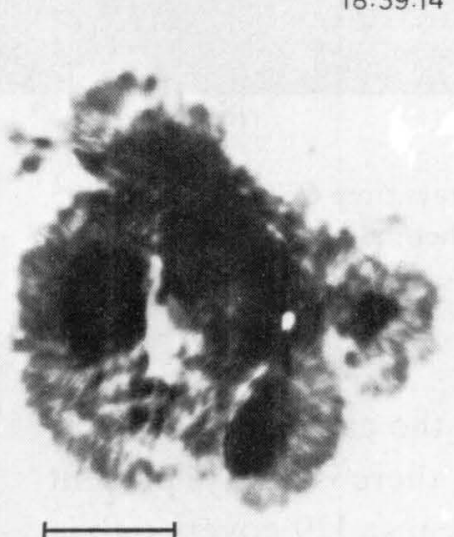

$20,000 \mathrm{KM}$

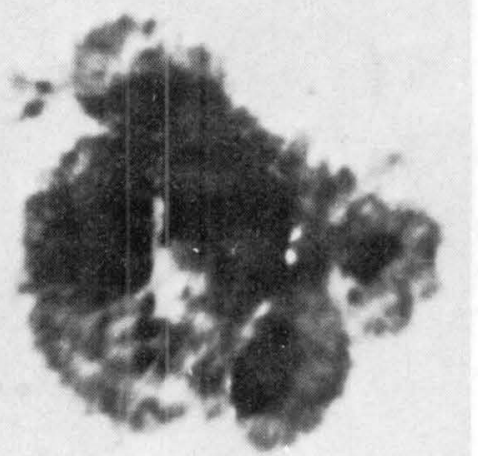

$18: 39: 34$

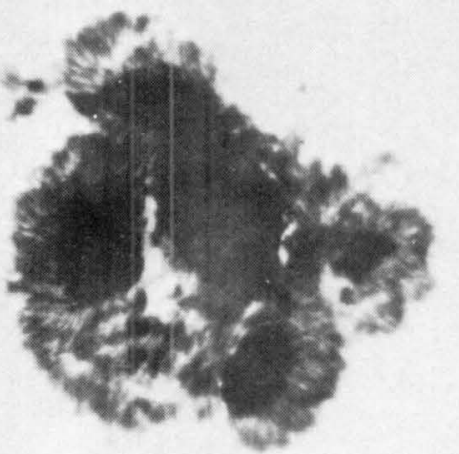

$18: 39: 44$

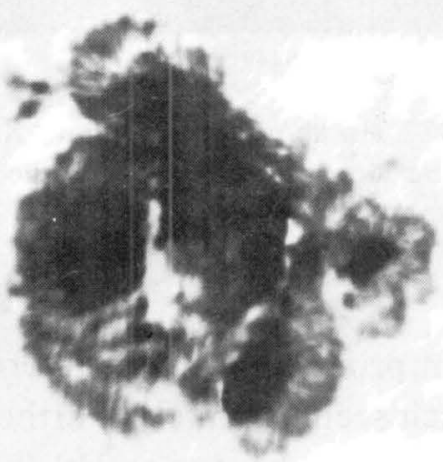

$18: 39: 54$

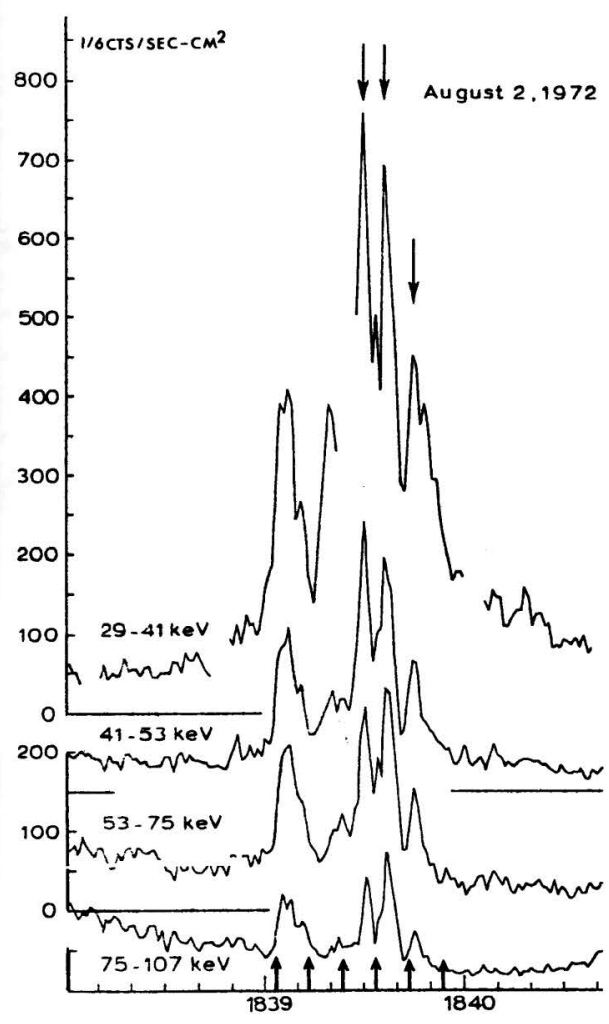

- TIME (UT)

Fig. 1. Fast flashes in $\lambda 3835$ observed in the 2 August, 1972 fiare, and TD-1A X-ray pulses. There is a general connection between the two. The filter is $15 \AA$ wide, centered at $\lambda 3835$. See Zirin and Tanaka (1973) for details.

the $\lambda 3835$ emission was well correlated in time with $\mathrm{H} \alpha$, peaking at the same time, 20:03. This time was also the peak of the soft $X$-rays measured by Solrad. The peak $\mathrm{H} \alpha$ intensity is $5.6 \times$ background, while the $\lambda 3835$ intensity is $1.4 \times$ background. Corrected for bandpass, this gives almost equal intensities for $\mathrm{H} \alpha$ and $\lambda 3835$. Zirin and Tanaka concluded, and Roy (1976) concurred, that the $\lambda 3835$ brightening might well be due to $\mathrm{H} 9$, because it was unlikely that electrons could penetrate to 


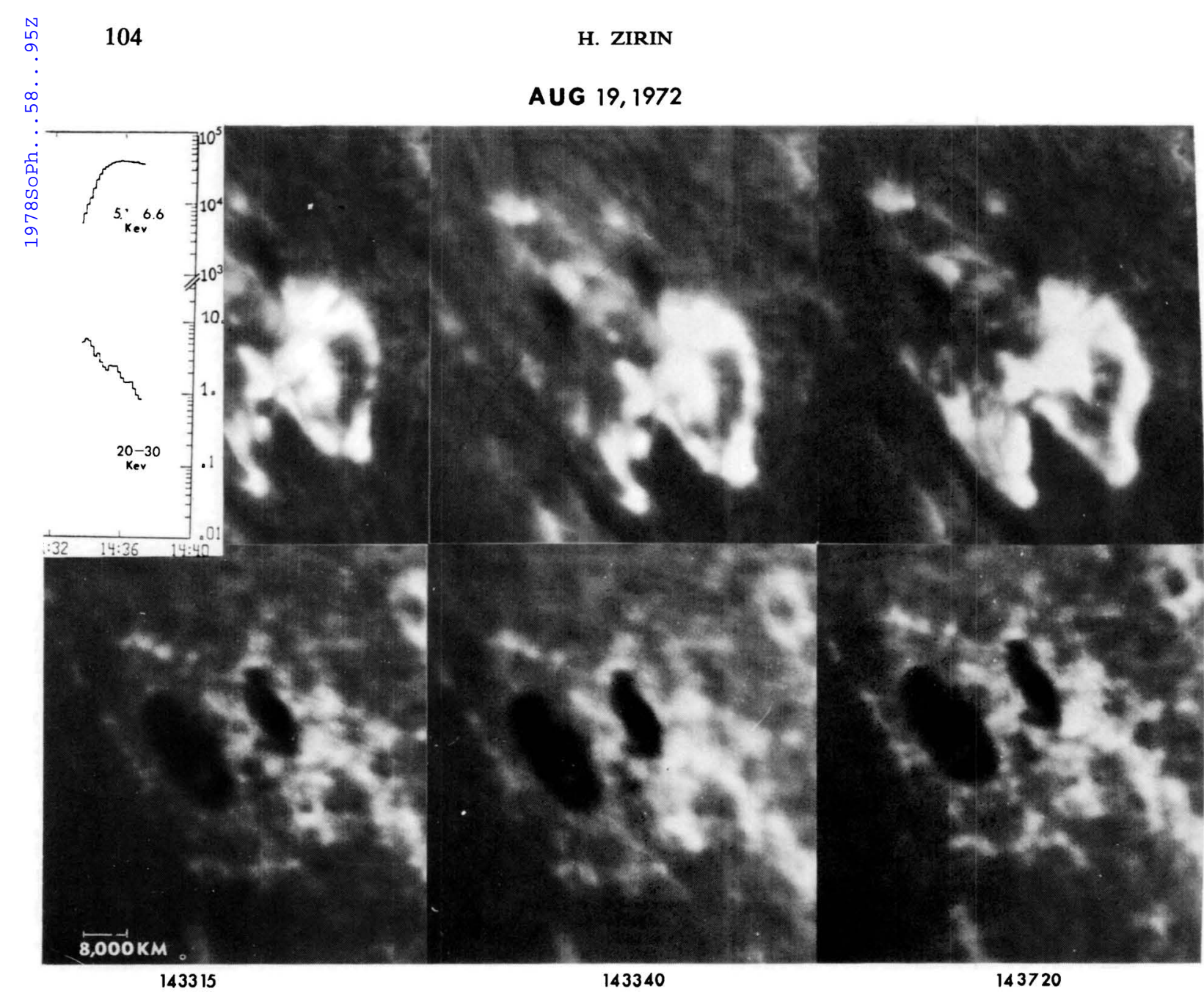

Fig. 2. An explosive flare 19 August, 1972, $\mathrm{H} \alpha$ above, $\lambda 3835$ below; X-rays from OSO-7. The $\lambda 3835$ emission occurs just right of the right hand spot, and is first seen in the thermal phase. Pileup distorts $20-30 \mathrm{keV}$ when $5.1-6.6 \mathrm{keV}>10^{4}$.

the required depth for continuum production. If that were the case, our measurements could imply $\mathrm{H} \alpha \cong \mathrm{H} 9$, which seems unlikely. Further there is always present a bright network in $\lambda 3835$ which cannot be due to H9 (because H9 covers only a fraction of the bandpass and the network is dark in the higher hydrogen lines). Although it is possible that the fast flashes in the 2 August event were due to H9, the close association of the three slower events with the SXR flux bespeaks a heating of the low chromosphere by the thermal electrons. If this blue continuum covers about $500 \AA$, we get an energy of $2 \times 10^{29} \mathrm{erg}$ for the 19 August, 1972 flare, similar to $\mathrm{H} \alpha$.

\section{Description of Individual Flares}

The preceding discussion is best clarified by description in detail of some distinctive flares. Times are all in Table I. I present in this section detailed data on the 
following flares with the following properties:

(a) 11 September, 1970 limb flare, HXR spike;

(b) 15 June, 1970 HXR spike, disk, multiple point;

(c) 28 June, 1970 complex disk event, multiple spike, Moreton wave;

(d) 10 February, 1972 limb eruption, complex, long decay;

(e) 16 December, 1972 disk surge;

(f) 28 May, 1970 single bright ball, HXR spike;

(g) 18 and 19 January, 1970 homologous, slow, 'thermal';

(h) 18 May, 1972 large, 2 strand, impulsive.

\section{(a) 11 September, 1970 limb flare (Figure 3)}

Limb flares are particularly desirable for understanding X-ray bursts, because we are not confused by radiation from the disk. In this case:

- the active region was behind the limb; all radiation comes from above the surface.

- there were several flares, in perfect time coincidence with several bursts. We assume the X-rays were closely related spatially to the $\mathrm{H} \alpha$ emission.

- the main spike event, lasting about 10 seconds, coincided with a sharp brightening and break-up of an existing loop in the same period.

As can be seen in Figure 3, there were 3 X-ray bursts, each of which corresponded to a different $\mathrm{H} \alpha$ brightening. The times, which are given in Table I, show a perfect simultaneity for the start of each event. Because of clouds, the 23:07 and 23:09 flares were only observed with our low resolution telescope; on the 23:15 flare we have $5 \mathrm{~s}$ time resolution in $\mathrm{H} \alpha$.

The 23:15 event was remarkable; an arch $10000 \mathrm{~km}$ long and $6000 \mathrm{~km}$ diameter rose from behind the limb a minute earlier, and suddenly lit up at the time of the HXR spike; it broke up at the end of the spike. It is possible that the entire flare took place in this arch. The $\mathrm{H} \alpha$ brightness was measured to be $9.5 \times$ the line center or $3.2 \times$ the nearby continuum. The total $\mathrm{H} \alpha$ emission, assuming a half width $\Delta \lambda=5 \AA$ is $5 \times 10^{26} \mathrm{erg} \mathrm{s}^{-1}$ or $10^{28}$ erg for the $20 \mathrm{~s}$ flare duration.

The X-ray emission from this flare was quite hard, fitting either an $E^{-2}$ power law or an exponential of the form exp $-(E / 30 \mathrm{keV})$. Using Brown's (1973) target thickness of $10^{20} \mathrm{H}$ atoms $\mathrm{cm}^{-2}$ for thick foil processes, the arch is thick if $N_{i}>$ $10^{11}$. The thick foil flux was $2.3 \times 10^{35} \mathrm{elec} \mathrm{s}^{-1}$ above $25 \mathrm{keV}$; for the $10 \mathrm{~s}$ lifetime of the burst, $8.6 \times 10^{27} \mathrm{erg}$ above $25 \mathrm{keV}$ were required, similar to the $\mathrm{H} \alpha$ flux.

The radio data are peculiar; a sizeable radio burst $(49$ sfu at $8800 \mathrm{MHz}, 4$ sfu at $2800 \mathrm{MHz}$ ) was reported during the small HXR burst at 23:10.6; but only a small (5 sfu at $2800 \mathrm{MHz}$ ) burst occurred at the main HXR spike at 23:16 (although meter-wave bursts were reported at the latter). Since there is no line of sight absorption at these wavelengths, we conclude that either the source of radio emission is lower than the HXR source and is occulted, or the radio source is quite small physically and there is high self-absorption. Use of the Ramaty-Petrosian (1972) tables with $B=100 \mathrm{G}$ predicts a peak emission around $2000 \mathrm{sfu}$. 


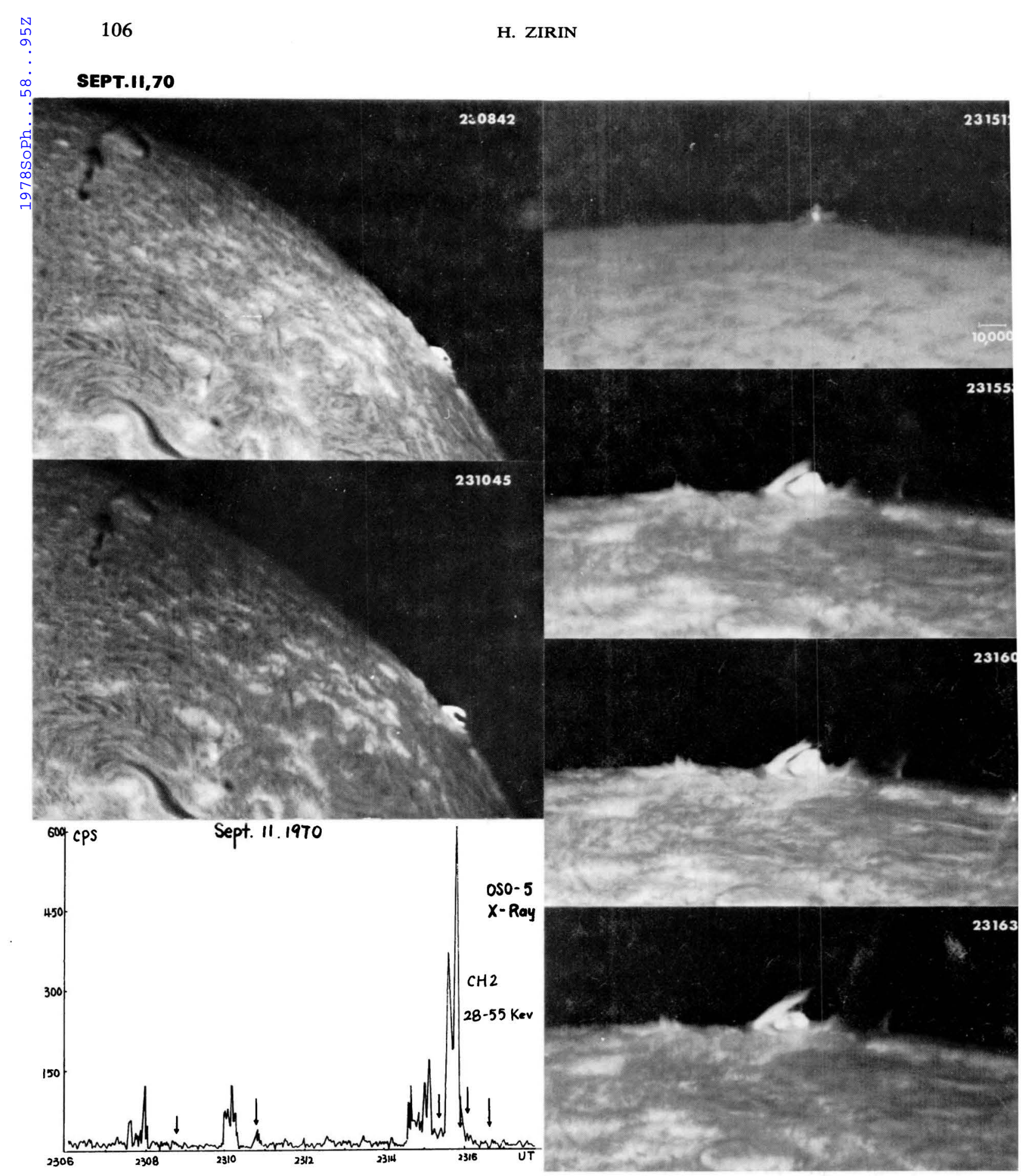

Fig. 3. Multiple limb flare 11 September, 1970; the first two frames are from Caltech, the rest are from Big Bear, rotated for clarity; all the emission is from the same limb position. The 23:15:12 frame is $\mathrm{H} \alpha+0.7 \AA$.

(b) 15 June, 1970 (Figure 4)

A fine example of impulsive flare with hard X-ray burst. Figure 4 shows the stage of $\mathrm{H} \alpha$ growth ( $\mathrm{N}$ top, $\mathrm{W}$ right) which is seen to be simultaneous with the burst recorded by OSO-5. A number of spots over an area $19000 \mathrm{~km}$ in diameter 

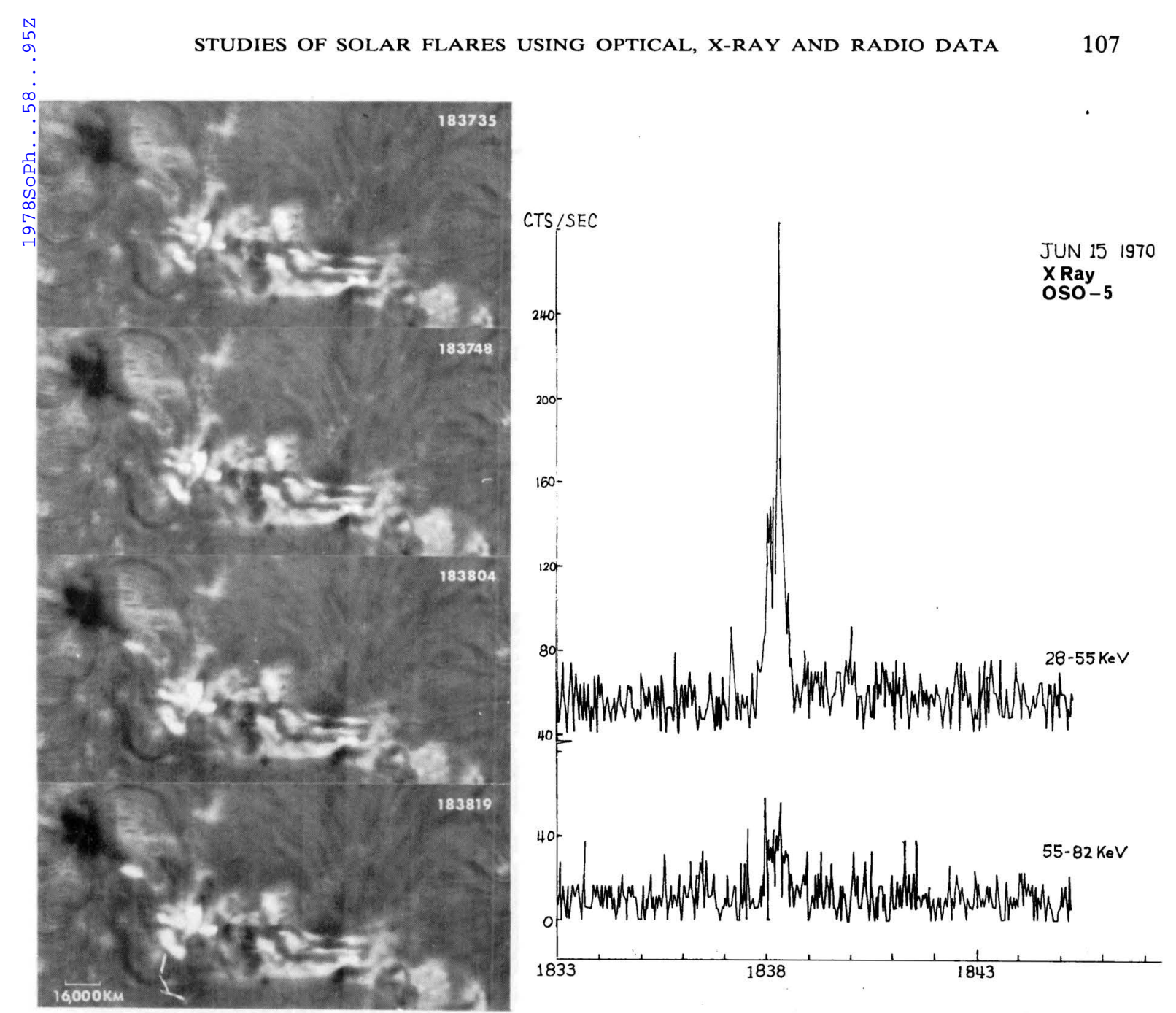

Fig. 4. Single impulsive X-ray burst, 15 June, 1970. The OGO-5 soft burst began 18:37:30, with the $\mathrm{H} \alpha$ precursor, as did the radio burst. Main $\mathrm{H} \alpha$ increase coincides with the main HXR spikes. Note that $\mathrm{H} \alpha$ is still very bright in the last frame, 15 min later. Note also that a distant point brightens in the first seconds.

brightened simultaneously, but at the peak of the burst a point $30000 \mathrm{~km}$ away (far left) also brightened. The hard X-ray spike began at 18:37:50, peak at 18:38:13 in very sharp spikes. A low $\mathrm{H} \alpha$ and SXR increase began at 18:37:22; as is apparent from Figure 4, there was a sudden $\mathrm{H} \alpha$ increase apparent at 18:38:04, with peak $\mathrm{H} \alpha$ at $18: 38: 19$, followed by almost constant brightness for several minutes (to 18:42) and then fade by $18: 50$.

In this case we see the $\mathrm{H} \alpha$ rise was simultaneous with the HXR flux, but the $\mathrm{H} \alpha$ brightness remained high with the SXR flux for some minutes; the increase in $\mathrm{H} \alpha$ emission came with the hard electrons, and that emission was maintained by the soft electrons. This contrasts with the elevated flare of 11 September; the difference is that we here see the chromospheric emission produced by the thermal phase. The flare had several isolated optical bits, all of which were bright; we must be seeing the ends of flux loops. The four main bright points could well be the ends of an $X$. 
The measured $\mathrm{H} \alpha$ area at maximum was $9.2 \times 10^{17} \mathrm{~cm}^{2}$; the $\mathrm{H} \alpha$ flux (assuming $\Delta \lambda=5 \AA$ ) was $2.4 \times 10^{26} \mathrm{erg} \mathrm{s}^{-1}$. The $\mathrm{X}$-ray spectrum fit a power law with $\gamma=3$, and the thick foil electron input was $4.6 \times 10^{27} \mathrm{erg} \mathrm{s}^{-1}, 10$ times greater; but the $\mathrm{H} \alpha$ event lasted at least 10 times as long. The radio burst was simultaneous with the hard X-rays, peaking at 200 sfu between 8800 and $10700 \mathrm{MHz}$.

(c) 28 June, 1970 (Figure 5; $\mathrm{N}$ top, $\mathrm{W}$ right)

A large, complex flare, with a long, many spiked hard burst. The SXR burst began at 19:41, with $\mathrm{H} \alpha$ increasing simultaneously. After HXR onset at 20:00.2, a complex series of brightenings took place. The first spikes at 20:01 produced a great increase in brilliance, which spread with more spikes, and the last, at 20:05, corresponded to emission of a Moreton wave, seen moving out to the bottom of the frame. A type II burst was reported at 20:07.5 by Harvard. The last frame shows a

JUN 28, 70

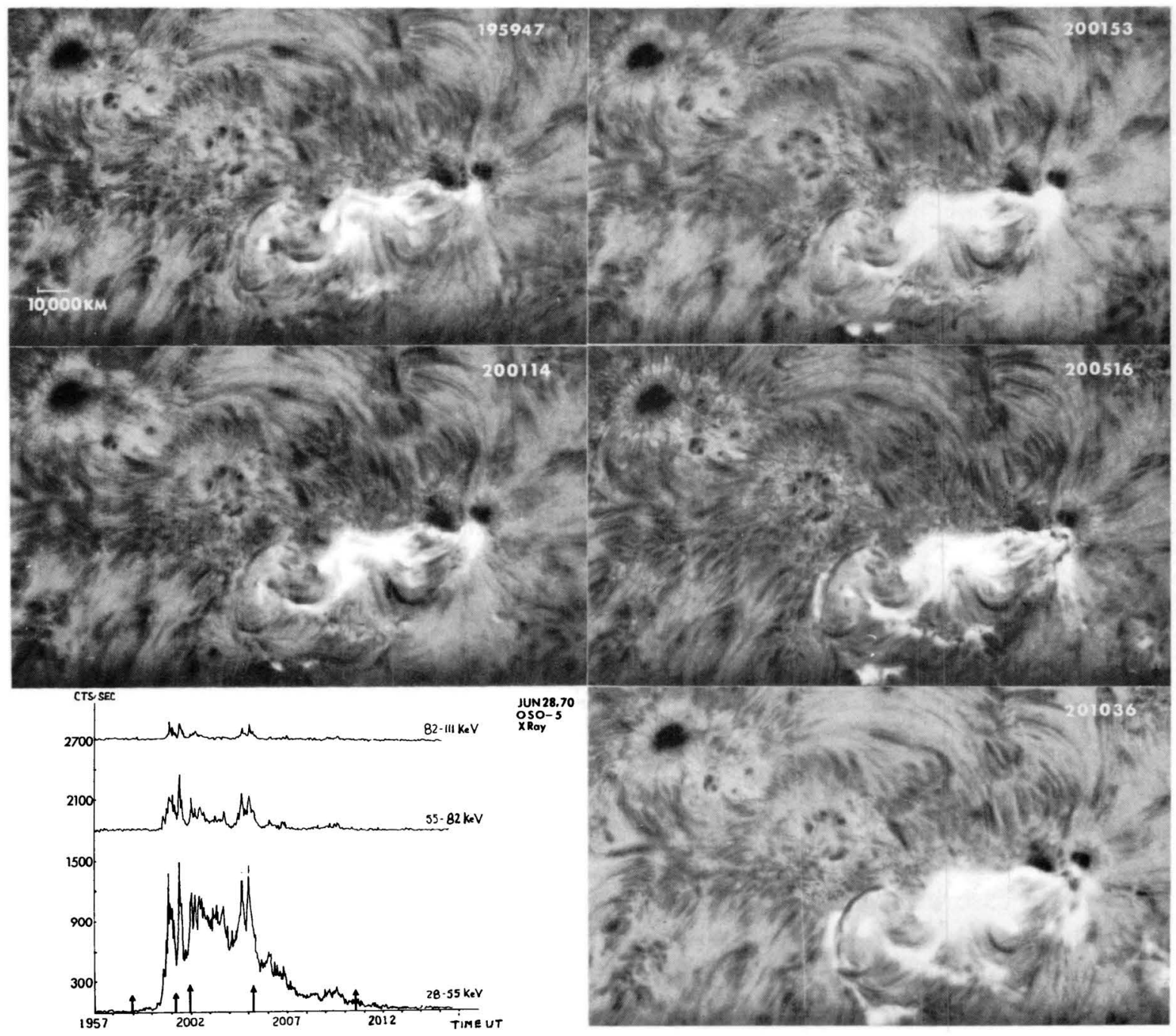

Fig. 5. Large flare 28 June, 1970 grows and grows, but X-ray flux is constant - thus $\mathrm{H} \alpha$ measures rate of electron energy deposition. $\mathrm{H} \alpha-0.6 \AA$. W at right, $\mathrm{N}$ top. The flare is in an EFR erupting across the $p$ spot of a bipolar group. 
separate eruption in the following (left) part of the flare and also corresponds to soft $\mathrm{X}$-ray maximum.

The many spikes in the X-ray burst (which are mirrored by the radio burst) are of the sort that have been termed quasi-periodic by some authors. It is hard to accept this view. Although we cannot show a one-to-one correspondence of the spikes with $\mathrm{H} \alpha$ development, it is clear that the flare spreads irregularly in this period with release of more and more energy, and rather than a repetitive phenomenon we are seeing a series of bursts of electron acceleration. Although the overall $\mathrm{H} \alpha$ flux grew, the X-ray flux remained the same; the $\mathrm{H} \alpha$ must be integrating the electron energy input.

The 28 June flare was one of a series which occurred in this spot group. They were occasioned by the eruption of an emerging flux region (EFR) across the $p$ spot of an extended old region. The $f$ spot of that region is seen to the upper left of the 2 spots at the right of the flare, one (furthest right) is the $p$ spot of the EFR and the other, the old $p$ spot. The flare itself covered the emerging flux region. It is interesting that, although the flare at first was not much bigger than some of our other flares, the X-ray flux was already 2 or 3 times greater. Thus the primary release in big flares is more intense, although of course more energy is released as the flare grows.

\section{(d) 10 February, 1972 (Figure 6)}

This flare, observed by OSO-7, gives an impression of the great complexity of large limb flares. In the first frame a filament is seen overlying an active region; at 23:00 it became active, at 23:10 it began rising. In the next frame we see the filament rising, brightening has just begun at one end, and the SXR burst is beginning. At 23:28 the hard burst began, accompanied by rapid brightening; in the third frame we see intense brightening at both ends of the region. Intense rotation and twisting appeared at the left with a bright elevated mound pushing up from the surface. The maximum brightness was reached at the last frame; the apparent peak of the hard burst at that time is observed by pileup. A $\mathrm{cm}$ burst was reported as well as type II metric burst at 23:35. The $\mathrm{cm}$ bursts are reported with peaks at 23:32 and 00:05, the latter presumably associated with the soft X-ray peak. The filament reformed the next day. Peak brightness was 8 times the chromosphere or 2.7 times the continuum. At no time was the surface occulted.

The filament eruption which began this flare led to considerable mass motion in the $20 \mathrm{~min}$ preceding the $\mathrm{X}$-ray burst, yet no $\mathrm{H} \alpha$ brightening was seen until the $\mathrm{X}$-ray burst began. It is therefore plausible that the $\mathrm{H} \alpha$ emission was excited by the electrons which produced the X-ray burst; one could further conclude that the electrons were only present in the parts of the flare where $\mathrm{H} \alpha$ emission was seen. The calculations of Section 6 suggest that if the electron flux penetrates a filament structure, strong $\mathrm{H} \alpha$ emission must result.

The soft X-ray burst had a long tail, lasting $9 \mathrm{hr}$. These long tails are typically observed after filament eruptions or very large flares. Since the Big Bear data end 


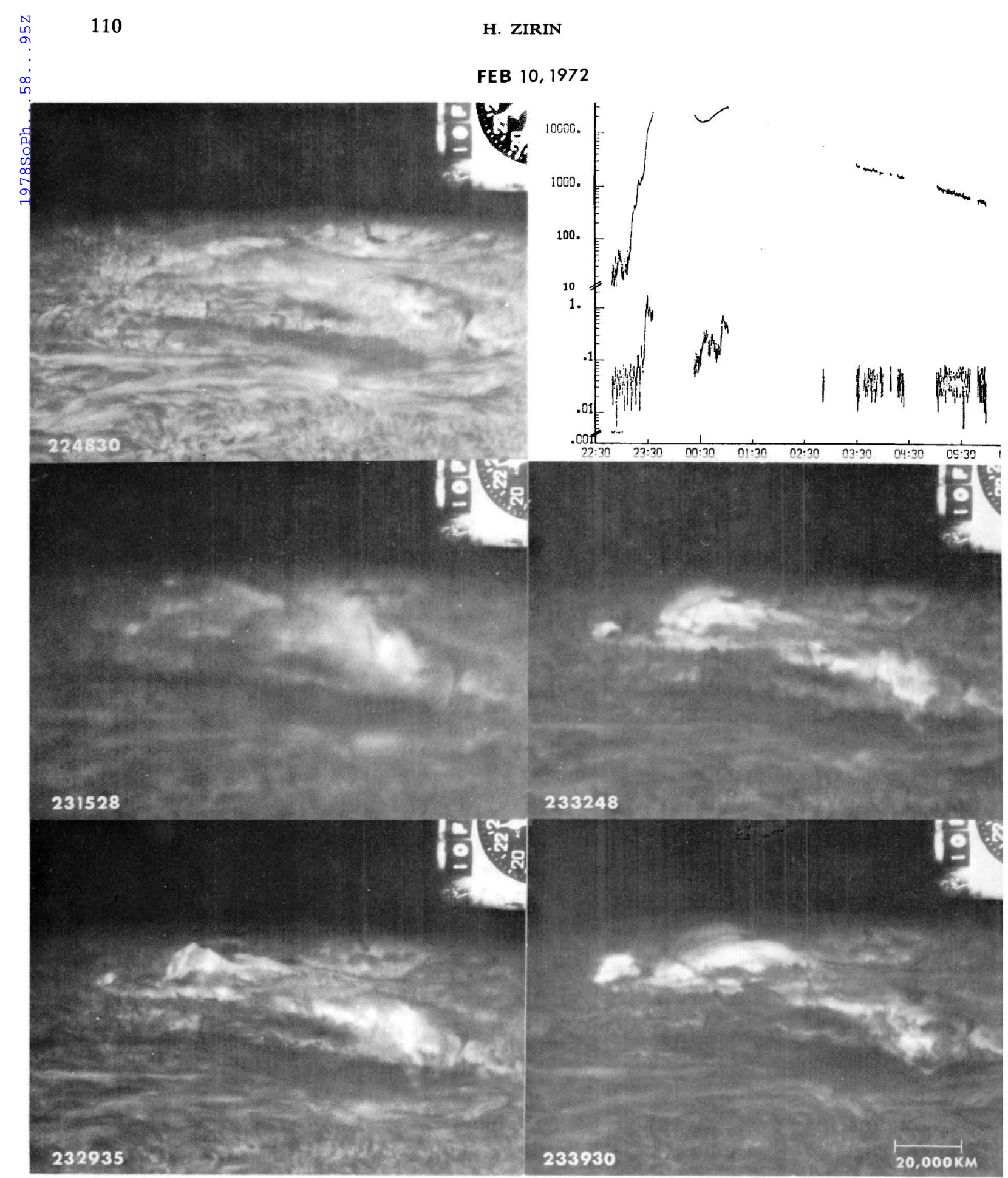

Fig. 6. Complex limb flare, 10 February, 1972 showing the extended decay pattern of a filament eruption. Pileup when 5.1-6.6>104.

at $0^{\mathrm{h}} \mathrm{UT}$ we cannot follow details, but assume the filament eruption produced an extensive coronal event.

(e) 16 December, 1972 (Figure 7)

In a bipolar spot group a bright surge came out of the $f$ spot; the HXR began just at 


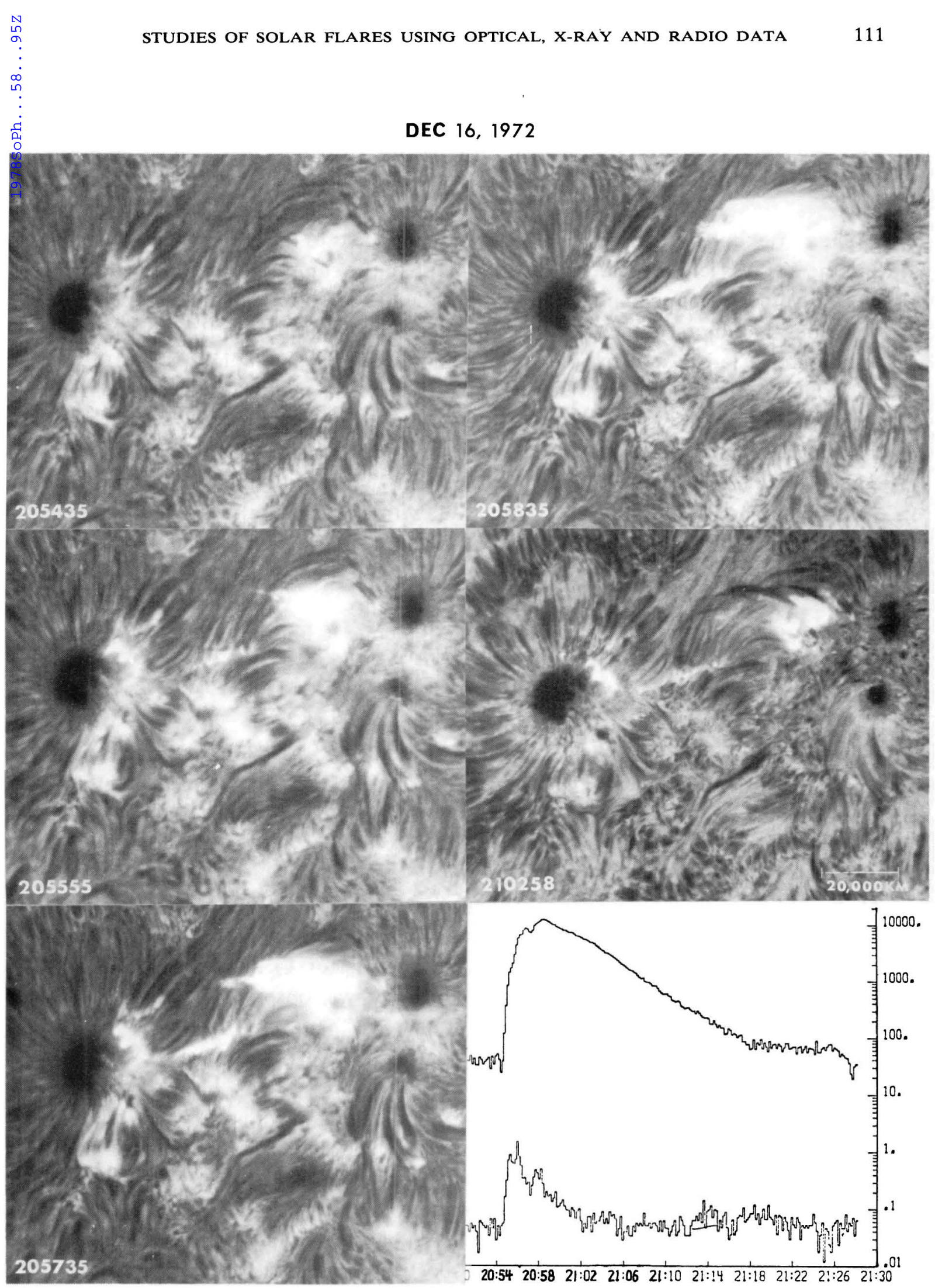

Fig. 7. Surge flare, 16 December, 1972. The flare is connected with a bright surge. 
the first frame of Figure 7, and peaked at the second frame, with the surge still growing. Maximum surge brightness occurred toward the end of the HXR burst. At the same time points on the surface between the two spots are seen to brighten. Inspection of the fifth frame shows these points connected by fibrils to the surge area.

The X-ray burst and flare were probably connected to the material in the surge, and the $\mathrm{X}$-rays were coincident with beginning of the surge. The energetic particles must have been trapped and accelerated inside the surge region, and escaped onto field lines that intersect the surface as the other $\mathrm{H} \alpha$ bright points. But note that the brightening at other surface points peaked with the SXR burst and was most likely a thermal conduction effect. Many flare models have been advanced which depend on reconnection above the surface, with energy streaming to the surface. In this case, as in some of the preceding, the energetic electrons must have been trapped and accelerated in the $\mathrm{H} \alpha$ emitting region, namely the early stages of the surge.

A cm burst of about $40 \mathrm{sfu}$ was observed, with a sharp cutoff below $2000 \mathrm{MHz}$. No metric burst was reported. This is expected from a flare in which most of the material appears trapped in a limited field. Had there been a flare source at greater heights, we should have seen emission at lower frequencies. The event appears confined to the region of visible $\mathrm{H} \alpha$. Simultaneous K line films show'essentially identical behavior in the $\mathrm{K}$ line.

\section{(f) 28 May, 1970 (Figure 8)}

This was a classic impulsive flare observed by OGO-5. At 01:20:55 nothing was visible. A brilliant point flash occurred in the three frames shown, coincident with the spikes seen in three hard channels. The greatest increase occurred between the first and second frames. The second part of the X-ray bursts (peak 01:23:30) was a thermal event possibly associated with the bright surge we see beginning on the 01:22:10 frame. No '2-strands' or structure are visible. The diameter of the bright ball was $16000 \mathrm{~km}$. Although it does not show in centerline, the off-band pictures show a satellite sunspot under the flare. A cm burst of 44 flux units, peaking at $9600 \mathrm{MHz}$ and sharply falling to lower frequencies, was observed. Nearly identical flares occurred here at 22:03, 22:49 and 02:07 UT.

\section{(g) 18-19 January, 1972}

This case (Figure 9) involves two flares in a complex region with a $p$ spot overtaking a bipolar group. The first flare shown, on 18 January, had a very small HXR component; the second, on 19 January, was a large flare with strong X-rays in all channels, but a generally soft spectrum, no doubt due to the slow rise. It has all the spatial characteristics of a large impulsive flare, but is slow and 'thermal'. The radio flux was only $35 \mathrm{sfu}$ at $8800 \mathrm{MHz}$ and the spectrum suggests a purely thermal burst. The two flares were similar in form, each preceded by activation of a filament along the neutral line. Although the HXR looks like a pileup effect for 19 January, the SXR flux is below $10^{4}$, so we probably see true HXR emission. 

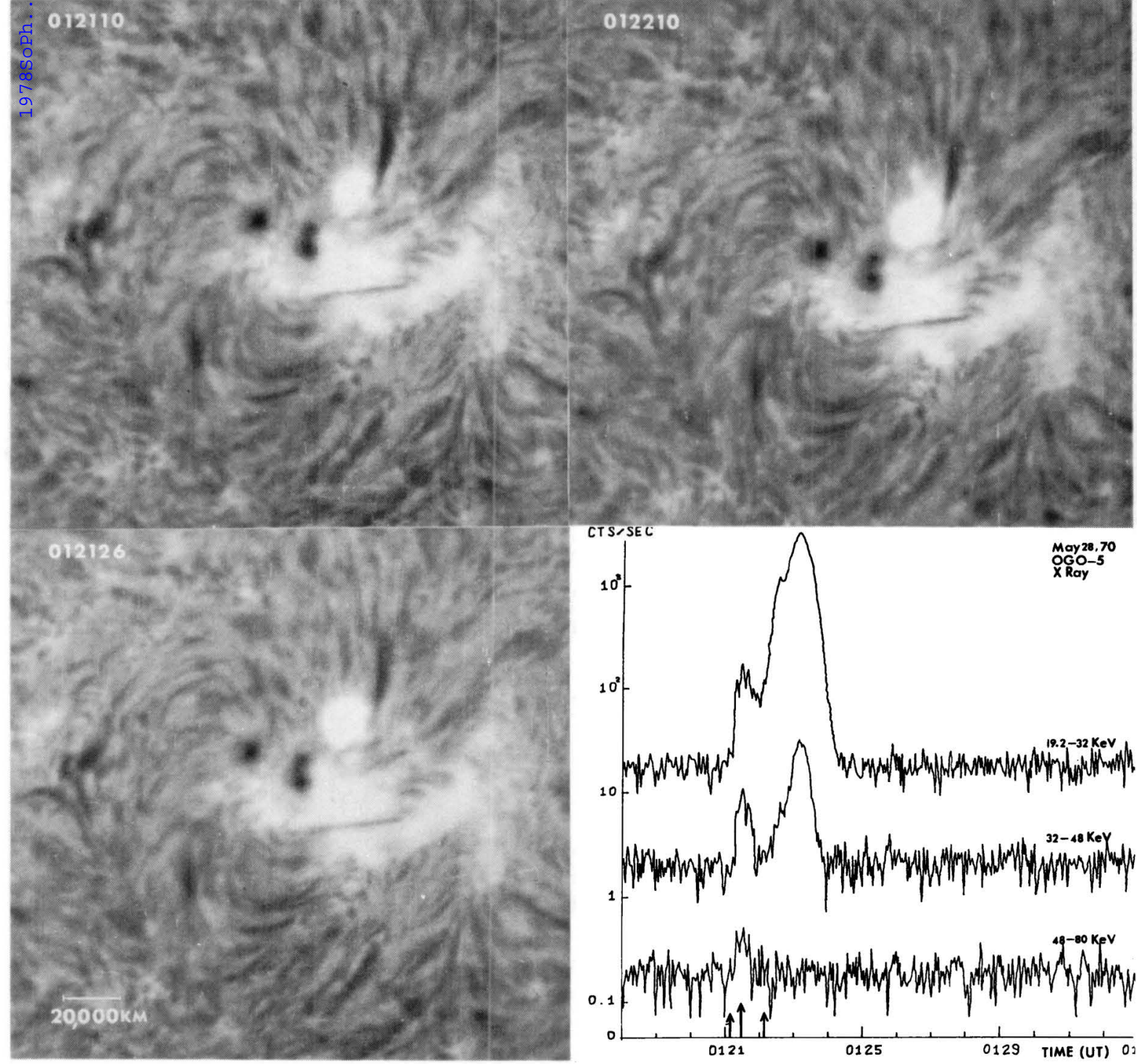

Fig. 8. Point-like flare, 28 May, 1970, except the 'point' is $15000 \mathrm{~km}$ across. The second, softer burst is from a bright surge that come out - its start is seen in the third frame.

(h) 18 May, 1972

This flare (Figure 10) is of interest because two identical flares occurred within two hours, and because peak $\mathrm{H} \alpha$ intensity occurs at the end of the X-ray burst. The X-ray data from TD-1A have been published by Hoyng (1975). The first flare at 14:06 was only observed by our full disk monitor, but is substantially identical in appearance to the second, which is illustrated in Figure 10. The main rise in brightness occurred between 16:17:14 and 16:17:45, substantially the interval of the HXR burst. The flare was brightest on the fourth frame of Figure 6 near the end of the burst, but this was also the peak of the HXR burst. The radio bursts with the two flares were sizeable, $300 \mathrm{sfu}$ at $14: 06$ and $200 \mathrm{sfu}$ at $16: 17$, with strong high 


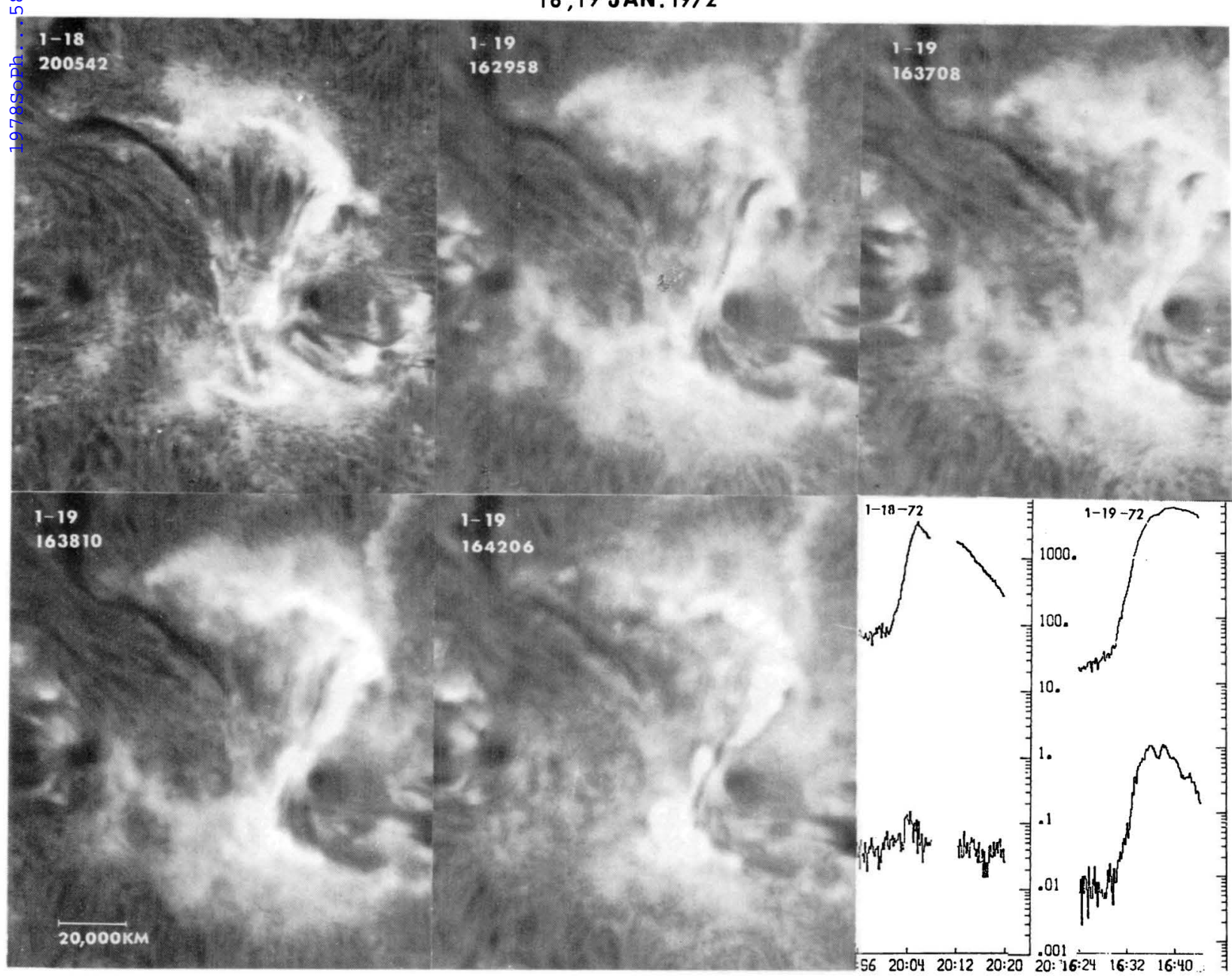

Fig. 9. Two 'thermal' or slow flares in the same region on successive days.

frequency components. In line with the closed appearance of the lines of force, there were no metric or dekametric bursts.

In the first flare the greatest $\mathrm{H} \alpha$ rise was between 14:06:03 and 14:06:15, the same as the greatest HXR increase. In both cases a precursor appeared $90 \mathrm{~s}$ before the HXR burst at 14:04:45 in the first, and 16:15:20 in the second. However the steep $\mathrm{H} \alpha$ increase is simultaneous with HXR to a few seconds. The spot separation is $105000 \mathrm{~km}$. The distance from end to end of the flare is $55000 \mathrm{~km}$; since the $\mathrm{H \alpha}$ rise was almost simultaneous everywhere, the exciting agents must have traveled at least $5000 \mathrm{~km} \mathrm{~s}^{-1}$ and therefore must have been electrons.

It is instructive to compare this event with the 11 September, 1970 flare. Hoyng (1972) gives the flux above $25 \mathrm{keV}$ as $F_{25}=10^{36}$ electrons s ${ }^{-1}$, and the total energy above $25 \mathrm{keV}$ as $P_{25}=2.3 \times 10^{30} \mathrm{erg}$. For 11 September these values are $F_{25}=$ $2 \times 10^{35}$ electrons s ${ }^{-1}$ and $P_{25}=8.7 \times 10^{26}$. Although the peak fluxes differ by only a factor 5, the longer duration of the 18 May flare makes the difference. The $\mathrm{H} \alpha$ intensity for 18 May $\left(A=5.3 \times 10^{18} \mathrm{~cm}^{2}, I / I_{c}=3, \Delta \lambda\right.$ assumed $\left.5 A\right)$ was $7 \times$ 
MAY 18.1972
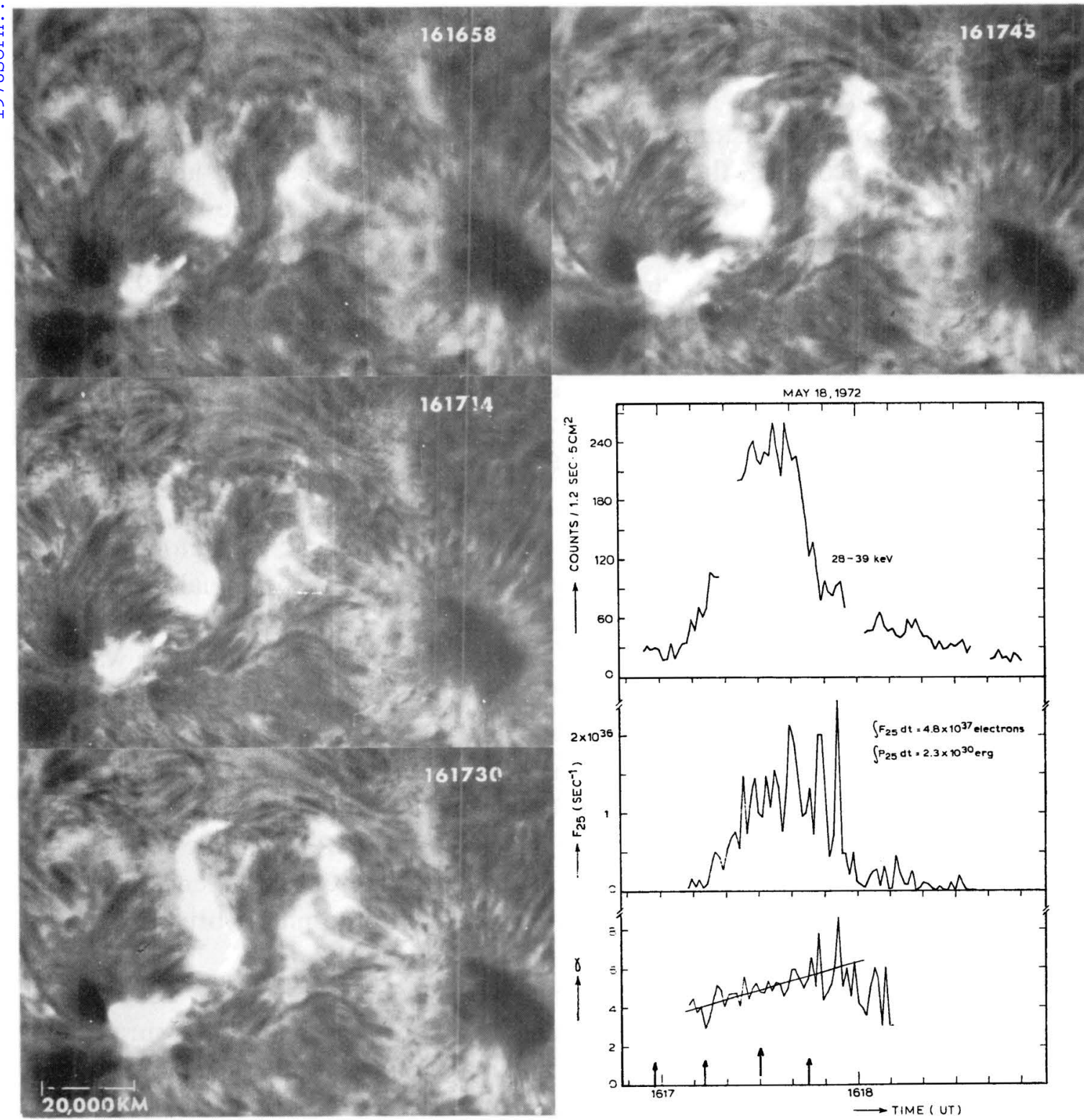

Fig. 10. One of two homologous flares 18 May, 1972. Despite its large size, the flare rose to maximum in $30 \mathrm{~s}$.

$10^{26} \mathrm{erg} \mathrm{s}^{-1}$, about the same as 11 September, but the longer duration of the $\mathrm{H} \alpha$ (300 s) gives total $\mathrm{H} \alpha$ emission of $2 \times 10^{29} \mathrm{erg}$, one tenth of $P_{25}$.

\section{Measured Flare Brightness in $\mathbf{H \alpha}$}

There is some interest in the exact value of $\mathrm{H} \alpha$ intensity. I measured this in a number of the flares studied, using the calibrated step wedge as a reference. Care was taken to reject stray light and to limit the regions measured to the most intense 
points. We have no data on line widths, but simultaneous movies $0.7 \AA$ from line center show little difference. Some flares were measured on a microdensitometer but most were measured on an overhead $35 \mathrm{~mm}$ projector using a photodiode and a mask in the film plane to reject scattered light. For a test flare these measurements agreed with the microdensitometer.

I attempted to compare the peak $\mathrm{H} \alpha$ intensity from two flares of the same SXR flux and different HXR fluxes. Although it is hard to find sizeable thermal flares with no hard X-rays, a few cases were found in the OSO-7 data. A thermal flare on 25 September, 1972 with no hard X-rays and one on 21 September, 1972 were measured; since they are on the same roll of film the comparison is reliable. Both had $800 \mathrm{ph}\left(\mathrm{cm}^{2} \mathrm{~s} \mathrm{keV}\right)^{-1}$ in the $5.1-6.6 \mathrm{keV}$ channel, the $9 / 21$ flare had $0.2 \mathrm{ph}$ $\left(\mathrm{cm}^{2} \mathrm{~s} \mathrm{keV}\right)^{-1}$ in the $20-30 \mathrm{keV}$ channel, the other, none (i.e., not exceeding $4 \times$ less). The areas were similar. Surprisingly, in each case the peak $\mathrm{H} \alpha$ intensity was $2.8 \pm 0.3 \times$ the chromospheric intensity. Since the $\mathrm{H} \alpha$ filter transmission at centerline is measured to be $\frac{1}{3}$ the intensity at $+1 \AA$; at the latter point the theoretical intensity is $70 \%$ of continuum except for enhanced side bands; $I$, therefore, assume that the centerline $\mathrm{H} \alpha$ background is $\frac{1}{3}$ the continuum. Thus, the actual intensity of these flares in terms of the continuum was about 0.9 .

Surprised by this result, I looked at other flares. Particularly interesting was the large thermal flare of 19 January, 1972 (Section 4g). The intensity of that flare was $4 \sqrt{2}$ times the chromosphere background, or $1.8 \times$ continuum. A comparable non-thermal flare on 11 April, 1972 was 8 times the background chromosphere, essentially the same. The 10 February, 1972 flare, just inside the limb again gave $8 \times$ chromosphere. It appears that there is no strong difference in the intensity of $\mathrm{H} \alpha$ emission of nonthermal and thermal disk flares; the only difference is in rise time. However our data begin to saturate at $12 \times$ chromospheric brightness, and this conclusion is less sure for the brightest flares.

Frame by frame measurements of brightness rise were made on some flares. Although one might expect visual estimates of rise time to be more accurate, the photometric measurements of beginning and maximum time were essentially identical with the visual ones.

\section{Production of $\mathrm{H \alpha}$ Emission}

The results of the preceding section may be summarized as follows:

(1) The $\mathrm{H} \alpha$ emission and HXR burst are simultaneous to a few seconds.

(2) The separate $\mathrm{H} \alpha$ sources must be excited by an agent moving at least $5000 \mathrm{~km} \mathrm{~s}^{-1}$.

(3) Most of the $\mathrm{H} \alpha$ emission comes from elevated sources which fade with the HXR; the surface $\mathrm{H} \alpha$ lasts with the SXR burst.

Since $\mathrm{H} \alpha$ and HXR are simultaneous in time and duration, the high speed of the $\mathrm{H} \alpha$ exciter could only be fit by the electrons or by some special high speed wave. Thus initial $\mathrm{H} \alpha$ flash must be produced by the same electrons which produce the HXR burst, incident on the elevated prominence-like material. This is different 
from the usual picture, such as that analyzed by Brown (1973) and Canfield (1974), where the radiation from a chromosphere superheated by flare particles is considered.

In fact, Brown et al. (1978) have essentially shown that one cannot fit the observed $\mathrm{H} \alpha$ line from at least the 7 August, 1972 flare with simply a heated atmosphere. The typical flare $\mathrm{H} \alpha$ line (we have other unpublished spectra similar to the 7 August spectra) is very wide, typically $5 \AA$ half-width, with no central reversal. The thermal profiles of Brown et al. are narrow and self-reversed, and are in excellent agreement with post maximum $\mathrm{H} \alpha$ profiles, agreeing with our concept that electron bombardment has stopped in the late phase.

The $\mathrm{H} \alpha$ profile can only be explained by large turbulent motions of the order of $250 \mathrm{~km} \mathrm{~s}^{-1}$ or by line shifts due to the direct electron impact. Observations of turbulence in pre-flare prominences, surges, etc. never show the great $\mathrm{H} \alpha$ width of flares; such widths are only seeñ elsewhere in emission phenomena such as Ellerman bombs. Further, the films of these flares, although they show much motion, do not show more than $100 \mathrm{~km} \mathrm{~s}^{-1}$. On the other hand, we know from thermal spectrum measurements (Datlowe et al., 1974) that temperatures of $2 \times 10^{7} \mathrm{deg}$ are quickly reached in flares, at least for the electrons. Jefferies and Orrall (1965) proposed that the broad profiles are due to excitation by energetic protons. Such a process would work if the protons were present; however, in small flares such as those studied here there is little evidence for them. The following shows that there is a reasonable possibility that direct electron excitation and impulse can produce the observed $\mathrm{H} \alpha$ emission.

Bethe (1933) has summarized the theory of the impact of hard electrons on hydrogen atoms. For energies above $1 \mathrm{keV}$ the results vary little with energy; at $10 \mathrm{keV}$ the total cross-section is $4.26 \times 10^{-18} \mathrm{~cm}^{2}$, of which $6 \%$ goes to elastic collisions, $58 \%$ to excitation $(45 \%$ to $n=2)$ and $35 \%$ to ionization. About 30 proton-electron pairs are produced per primary electron.

In the 11 September, 1970 flare (4a) the arch was $6000 \mathrm{~km}$ in diameter and $10000 \mathrm{~km}$ long. Judging by our earlier measurements of such events (Zirin, 1962) a density of $10^{11}-10^{12} \mathrm{~cm}^{-3}$ is reasonable. The thick foil flux above $10 \mathrm{keV}$ was

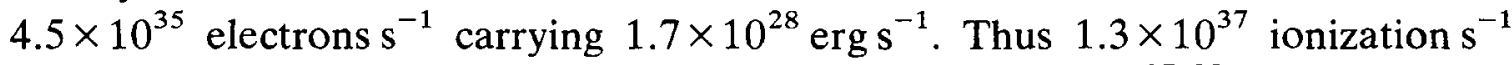
were produced, using Bethe's values. Since there were $3 \times 10^{37-38} \mathrm{H}$ atoms in the prominence, each atom was ionized once by direct or secondary impact in the $20 \mathrm{~s}$ burst lifetime.

On the other hand, if the $6 \%$ elastic collisions all heat the plasma, one finds it is heated at a rate of $10 \mathrm{eV}$ atom ${ }^{-1} \mathrm{~s}^{-1}$; after $20 \mathrm{~s}$ the atoms are at a temperature of $200 \mathrm{eV}$ or $2000000 \mathrm{deg}$ if there are no radiative losses. The radiative losses, however, are large, and the temperature may rise more slowly.

So for a brief impulsive flare the electron flux has ionized part of the atoms and heated the prominence to $10^{5}-10^{6} \mathrm{deg}$; in a longer flare the electron temperature will reach a much higher level.

Note that the electrons will only penetrate a few hundred $\mathrm{km}$ into the arch until it is more highly ionized. Since the arch is quite large by comparison and brightens 
simultaneously, we conclude that the arch is so filamented that the electrons permeate the entire structure. In this case it is possible, indeed probable, that electron heating is concentrated in a limited area, that this limited sample is heated to a much higher temperature than that quoted, equipartition of protons and electron energy is achieved, and the broad $\mathrm{H} \alpha$ is due to mixing of the high temperature protons and nearby unperturbed material.

As a measure of the parameters involved in $\mathrm{H} \alpha$ production, it is useful to consider the following facts. $\mathrm{H} \alpha$ emission will result from three principal sources: recombination and cascade, direct excitation from $1^{2} S$, and excitation from $n=2$. Calculation of the recombination rate for $n \geq 3$ shows that one-tenth of the recombinations occur on these levels; almost all of these lead to $\mathrm{H} \alpha$ emission. Since half the electron collisions lead to ionization, this converts $5 \%$ of electron energy to $\mathrm{H} \alpha$ (we assume the electron energy loss is the same for all collisions, elastic and inelastic).

The cross-section for excitation of $3 p$ is $7 \%$ of the total; only $\frac{1}{9}$ of these give $\mathrm{H} \alpha$, thus converting an additional one percent of electron energy.

Finally, $45 \%$ of the energy excites $\mathrm{L} \alpha$; although there is almost no data on $\mathrm{L} \alpha$ emission from flares, the evidence suggests the $\mathrm{L} \alpha$ intensity is comparable to $\mathrm{H} \alpha$, presumably because of the great $\mathrm{L} \alpha$ optical depth. Hall (1971) observed values equivalent to $5 \times 10^{25} \mathrm{erg} \mathrm{s}^{-1}$ in a class 2 flare; less than the $\mathrm{H} \alpha$ flux. $\mathrm{L} \alpha$ and $\mathrm{H} \alpha$ are approximately equal in quasars (Zirin, 1978). This produces a large population in the $2^{2} P$ state from which local thermal electrons excite $\mathrm{H} \alpha$. The efficiency of this process depends strongly on the $\mathrm{L} \alpha$ optical depth; for $\tau>10^{2}$ in $\mathrm{L} \alpha$ the fraction of $\mathrm{L} \alpha$ photons leading to $\mathrm{H} \alpha$ becomes significant.

It is thus clear that ten to twenty percent of the original electron energy can be converted to $\mathrm{H} \alpha$. This is in accord with the measurements of Section 4. One must realize that the electron energy deduction from the X-ray data is subject to an error of a factor 2 or more either way, as are the $\mathrm{H} \alpha$ measurements.

\subsection{Fully IONIZED PLASMA}

We now consider the case where the flare is compressed from the corona or else the material has been heated to an extreme temperature from the preflare prominence. The only source of emission is the occasional recombination of $\mathrm{H}$ II. Since there is no $\mathrm{H}$ III, this is not a negligible source. As long as the $\mathrm{X}$-rays emission may be fitted by a thermal spectrum (either for 'thermal' or 'non-thermal' flares), we have a simple formula for $\mathrm{H} \alpha$ excitation formula (Zirin, 1955). The excitation of $\mathrm{H} \alpha$ is:

$$
\begin{aligned}
N(\mathrm{H} \alpha) & =N_{e} C_{\mathrm{H} \alpha} N(\mathrm{H} \mathrm{I}) \text { photon } \mathrm{cm}^{-2} \mathrm{~s}^{-1}, \\
& =N_{e} C_{\mathrm{H} \alpha} \frac{N(\mathrm{H} \mathrm{I})}{N(\mathrm{H} \mathrm{II})} N_{e}, \\
& =N_{e}^{2} C_{\mathrm{H} \alpha} \frac{\sum_{n} R_{K n}}{C_{1 K}}
\end{aligned}
$$


According to Bethe (1933) the ratio of $C_{13}$ to $C_{1 K}$ is 0.20 at $10 \mathrm{keV}$ and slowly varying. From $C_{13}$ only $\frac{1}{7}$ give $\mathrm{H} \alpha$, but if the flare is optically deep in $\mathrm{L} \alpha$ the Zanstra mechanism leads to all these collisions giving an $\mathrm{H} \alpha$ photon, hence we use $C_{\mathrm{H} \alpha}=$ $=C_{13}=0.2 C_{1 K}$. So

$$
N(\mathrm{H} \alpha)=0.2 N_{e}^{2} \sum_{n} R_{K n}
$$

In addition to collisional excitation, about $10 \%$ of the recombination lead to $\mathrm{H} \alpha$, so the factor becomes 0.3 :

$$
N(\mathrm{H} \alpha)=0.3 N_{e}^{2} \sum R_{K n} .
$$

To get the intensity we substitute the recombination formula, and multiply by $h \nu / 4 \pi$ and the thickness:

$$
I(\mathrm{H} \alpha)=N_{e}^{2} \times 7 \times 10^{-26} N_{e}^{2} T^{-1 / 2} L \mathrm{erg} \mathrm{cm}^{-2} \mathrm{~s}^{-1} .
$$

To compare with observations, in the 10 May, 1972 flare $T \sim 3 \times 10^{7}, N_{e}^{2} V=$ $=N_{e}^{2} L A=3 \times 10^{45}$. The area was $5 \times 10^{18} \mathrm{~cm}^{2}$, and we find

$$
I(\mathrm{H} \alpha)=7.4 \times 10^{-3} \mathrm{erg} \mathrm{cm}^{-2} \mathrm{~s}^{-1} \text { at } 3 \times 10^{7} \mathrm{deg} .
$$

The observed value is $I(\mathrm{H} \alpha)=12 \times 10^{6} \mathrm{erg} \mathrm{cm}^{-2} \mathrm{~s}^{-1}$. So the emission cannot come from the pure flare plasma unless $A$ is very much smaller than the observed $\mathrm{H} \alpha$ area, but of course we should then not see the $\mathrm{H} \alpha$ coming from such a big area.

Thus the $\mathrm{H} \alpha$ flare emission cannot be produced by a fully ionized plasma, compressed out of the corona, but must be due to excitation of partly neutral hydrogen, as set forth in the beginning of this section.

\section{Summary}

We find in a large variety of flares no delay between $\mathrm{H} \alpha$ and X-ray rise, and simultaneous brightening of distant sources that requires a fast moving exciter, presumably electrons. We find limb flares and others where vertical resolution is available show an elevated brightening as the impulsive flare, which fades (except in surges) when HXR emission ends. H $\alpha$ may continue near maximum after the HXR peak if the surface is seen and if the SXR maximum lasts beyond the HXR phase. Thus we propose that the impulsive phase in $\mathrm{H} \alpha$ is due to direct and secondary excitation of a pre-existing arch or prominence, while the 'thermal' phase is due to heating of the chromosphere.

Observations in $\lambda 3835$ show that large flares, with $5-6 \mathrm{keV}$ flux above $10^{4}$ photon $\mathrm{cm}^{-2} \mathrm{~s}^{-1}$ can produce brightening in the low chromosphere, but smaller ones cannot. Comparsion of $\lambda 3835$ and $\mathrm{H} \alpha$ fluxes suggest that $\mathrm{H} 9$ is not responsible for the emission, implying a continuum emission equal in flux to $\mathrm{H} \alpha$. The absence of brightening in smaller flares and the presence of a normal network 
brightening in $\lambda 3835$ suggest that back-conduction from the corona is not responsible for the quiet network brightening.

In disk flares there is no $\mathrm{H} \alpha$ brightness difference between flares with HXR spikes and SXR only. For a number of flares where $\mathrm{X}$-ray and $\mathrm{H} \alpha$ flux was measured, the $\mathrm{H} \alpha$ flux is typically one-tenth the electron energy above $10 \mathrm{keV}$.

\section{Acknowledgements}

I wish to thank Ron Moore for many discussions; John Barnard and David Kodama for collecting the data on OGO-5 events; and particularly the X-ray experimenters: K. Frost, P. Hoyng, D. Datlowe, M. Elcan, and S. Kane for making available their data.

This work was supported by NASA under Grant NGR 05-002-034, NSF under Grant ATM76-21132 and AFGL under Contract F19628-77-C-0106.

\section{References}

Bethe, H.: 1933, Handbook Phys. 24, 519.

Brown, J. C.: 1973, Solar Phys. 31, 143.

Brown, J. C., Canfield, R. C., and Robertson, M. N.: 1978, Solar Phys. 57, 399.

Canfield, R.: 1974, Solar Phys. 34, 339.

Chapman, G.: 1970, Solar Phys. 13, 78.

Datlowe, D. W., Elcan, M. J., and Hudson, H. S.: 1974, Solar Phys. 39, 155.

Frost, K., Dennis, B., and Lencho, R. J.: 1971, in Labuhn and Lust (eds.), New Techniques in Space Astronomy, 185.

Hall, L. A.: 1971, Solar Phys. 21, 167.

Heasley, J. N., Mihalas, D., and Poland, A. I.: 1974, Astrophys. J. 192, 51.

Hoyng, P.: 1975, Thesis, Utrecht.

Hoyng, P., Brown, J. C., and van Beek, H. F.: 1976, Solar Phys. 48, 197.

Jefferies, J. T. and Orrall, F. Q.: 1965, Astrophys. J. 141, 519.

Kane, S. R. and Anderson, K. A.: 1970, Astrophys. J. 162, 1003.

Lin, R. P. and Hudson, H. S.: 1976, Solar Phys. 50, 153.

Ramaty, R. and Petrosian, V.: 1972, Astrophys. J. 178, 241.

Roy, J.-R.: 1976, Solar Phys. 48, 265.

Vorpahl, J.: 1972, Solar Phys. 26, 397.

Zirin, H.: 1955, Smithsonian Contr. to Astrophys. 2, 13.

Zirin, H.: 1972, Solar Phys. 26, 393.

Zirin, H.: 1978, submitted to Astrophys. $J$.

Zirin, H. and Tanaka, K.: 1973, Solar Phys. 32, 173.

Zirin, H., Pruss, G., and Vorpahl, J.: 1971, Solar Phys. 19, 463. 